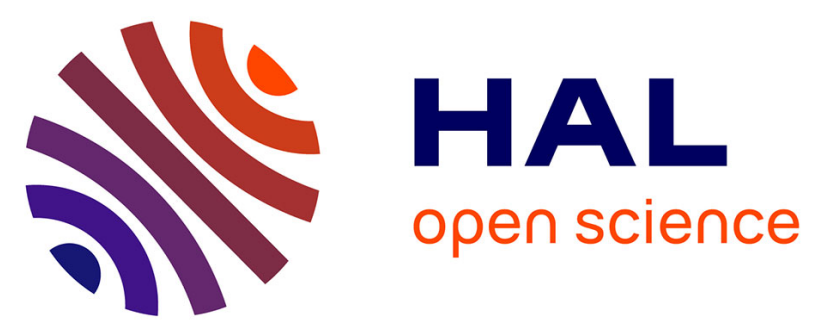

\title{
Generation of human muscle fibers and satellite-like cells from human pluripotent stem cells in vitro
}

Jérome P Chal, Ziad Al Tanoury, Marie P Hestin, Bénédicte Gobert, Suvi P

Aivio, Aurore P Hick, Thomas Cherrier, Alexander P Nesmith, Kevin K

Parker, Olivier P Pourquié

\section{To cite this version:}

Jérome P Chal, Ziad Al Tanoury, Marie P Hestin, Bénédicte Gobert, Suvi P Aivio, et al.. Generation of human muscle fibers and satellite-like cells from human pluripotent stem cells in vitro. Nature Protocols, 2016, 11 (10), pp.1833-50. 10.1038/nprot.2016.110 . inserm-01485521

\section{HAL Id: inserm-01485521 https://www.hal.inserm.fr/inserm-01485521}

Submitted on 8 Mar 2017

HAL is a multi-disciplinary open access archive for the deposit and dissemination of scientific research documents, whether they are published or not. The documents may come from teaching and research institutions in France or abroad, or from public or private research centers.
L'archive ouverte pluridisciplinaire HAL, est destinée au dépôt et à la diffusion de documents scientifiques de niveau recherche, publiés ou non, émanant des établissements d'enseignement et de recherche français ou étrangers, des laboratoires publics ou privés.

\section{(1) $(1) \Theta$}

Distributed under a Creative Commons Attribution - NonCommercial - NoDerivatives| 4.0 
***Final Author Version*** for Publication doi:10.1038/nprot.2016.110 at http://www.nature.com/nprot/journal/v11/n10/abs/nprot.2016.110.html

\section{Generation of human muscle fibers and satellite-like cells from human pluripotent stem cells in vitro}

Authors: Jérome Chal ${ }^{1,2,3,4, \#, ~ Z i a d ~ A l ~ T a n o u r y ~}{ }^{1, \#}$, Marie Hestin ${ }^{2,3,4}$, Bénédicte Gobert ${ }^{1}$, Suvi Aivio ${ }^{2,3,4}$, Aurore Hick ${ }^{5}$, Thomas Cherrier ${ }^{1}$, Alexander P. Nesmith ${ }^{6}$, Kevin K. Parker $^{6}$ \& Olivier Pourquié , $^{1,2,3,4, *}$

Affiliations:

${ }^{1}$ Institut de Génétique et de Biologie Moléculaire et Cellulaire (IGBMC), CNRS (UMR 7104), Inserm U964, Université de Strasbourg, Illkirch Graffenstaden, France.

${ }^{2}$ Department of Pathology, Brigham and Women's Hospital, 77 Avenue Louis Pasteur, Boston, Massachusetts, USA.

${ }^{3}$ Department of Genetics, Harvard Medical School, 77 Avenue Louis Pasteur, Boston, Massachusetts, USA.

${ }^{4}$ Harvard Stem Cell Institute. 77 Avenue Louis Pasteur, Boston, Massachusetts, USA.

${ }^{5}$ Anagenesis Biotechnologies, Parc d'innovation, 650 Boulevard Gonthier d'Andernach 67400 Illkirch Graffenstaden, France.

${ }^{6}$ Disease Biophysics Group, Wyss Institute for Biologically Inspired Engineering, School of Engineering and Applied Sciences, Harvard University, Cambridge, USA. \# equal contribution

* Contact Information: Olivier Pourquié, Ph.D.

Department of Genetics, Harvard Medical School and Department of Pathology, Brigham and Women's Hospital, 77 Avenue Louis Pasteur, Boston, MA, USA. email: pourquie@genetics.med.harvard.edu

Keywords: pluripotent stem cells, myogenesis, skeletal muscle, satellite cell, bioengineering, directed differentiation, embryonic stem cell, iPS 


\begin{abstract}
Progress towards finding a cure for muscle diseases has been slow due to the absence of relevant cellular models and the lack of a reliable source of muscle progenitors for biomedical investigation. Here, we report an optimized serum-free differentiation protocol to efficiently produce striated, millimeter-long muscle fibers together with satellite-like cells from human pluripotent stem cells (PSCs) in vitro. By mimicking key signaling events leading to muscle formation in the embryo, in particular the dual modulation of Wnt and Bone morphogenetic pathway (BMP) signaling pathways, this directed differentiation protocol does not require genetic modifications or cell sorting. Robust myogenesis can be achieved in vitro within 1 month by personnel experienced in human PSC culture. The differentiating culture can be subcultured to produce large amounts of myogenic progenitors amenable for numerous downstream applications. Beyond the study of myogenesis, this differentiation method offers an attractive platform to develop relevant in vitro models of muscle dystrophies, drug screening strategies, and to provide a source of cells for tissue engineering and cell therapy approaches.
\end{abstract}

\title{
INTRODUCTION
}

Until recently little progress has been made to differentiate human PSCs toward a myogenic fate. This in turn has hampered both the development of relevant human in vitro models of muscle diseases and the assessment of cell therapy approaches. Here we report an optimized directed differentiation protocol for in vitro production of mature muscle fibers and their associated progenitors from human PSCs. This is a detailed version of the protocol reported in Chal et al., $2015^{1}$ with a number of improvements including the expansion and cryopreservation of the hPSC-derived myogenic progenitors. By mimicking the early signaling events occurring during paraxial mesoderm specification in the embryo - in particular the simultaneous activation of Wnt and inhibition of BMP signaling pathways - this protocol recapitulates the essential steps of skeletal myogenesis in vitro in less than 30 days. The resulting fibers show spontaneous contraction and provide a niche for associated Pax7-positive satellite -like cells. An additional subculturing step allows for the preparation of proliferative myogenic 
populations that can be further amplified, cryopreserved or differentiated into muscle fibers. This protocol is readily amenable for multi-format in vitro cell assays and various downstream applications. All together, the recapitulation of myogenesis in a dish will be an invaluable tool for the muscle, stem cell, muscle physiology and pathology, and developmental biology communities for both basic and applied research.

\section{Development of the Protocol}

Directed differentiation methods aim at exposing PSCs to differentiation cues allowing the sequential recapitulation of key stages of paraxial mesoderm development and its differentiation into skeletal muscle. Early attempts to generate skeletal muscles used spontaneous differentiation of embryoid bodies, resulting in heterogeneous differentiation and low efficiency ${ }^{2,3}$. Progress in 2D- culture systems was slow until recently when manipulations of key signaling pathways involved in paraxial mesoderm specification were incorporated to differentiation protocols. In the embryo, Wnt signaling is required for paraxial mesoderm induction ${ }^{4-7}$ (for review ${ }^{8}$ ). In embryos mutant for Wnt3a or its targets $T$ or Tbx6, ectopic neural tubes form instead of the paraxial mesoderm in the posterior part of the embryo ${ }^{7,9-11}$. In PSC culture, Wnt signaling promotes mesodermal differentiation ${ }^{12-15}$ and several recent myogenic induction protocols rely on early Wnt activation ${ }^{1,16-19}$. Wnt signaling also acts upstream of the Fibroblast growth factor (FGF) pathway in paraxial mesoderm precursors of the tail bud, by triggering expression of the Fgf8 ligand ${ }^{20}$. Later on, at the somite level, secreted Wnts from surrounding tissues are also critical for dermomyotome specification (for review $\left.^{21}\right)$.

BMP signaling controls the medio-lateral identity of posterior mesoderm cells ${ }^{22-26}$. In amniote embryos, high BMP leads to the specification of more lateral tissues such as extraembryonic mesoderm, or lateral plate mesoderm (LPM), a tissue that contributes to the limbs and body wall mesenchyme and to the long bones of the limbs but which does not form skeletal muscle. Ectopic BMP signaling can divert cells fated to form paraxial mesoderm to a lateral plate fate in vivo ${ }^{22}$. Conversely BMP loss of function mutation 
leads to expanded paraxial mesoderm domain ${ }^{27}$. In vivo, the paraxial mesoderm is protected from BMP signaling produced by the LPM by the inhibitors Noggin and Chordin which are expressed by the notochord, the intermediate mesoderm and the dorsal somite ${ }^{24,25,28}$. In vitro, in absence of proper BMP signaling inhibition, the early paraxial mesoderm induced by Wnt signaling produces BMP4 and "drifts" by an autocrine effect to generate LPM derivatives (J.C., Z.A.T. and O.P., unpublished observation). At the heart of the protocol presented here lies the use of dual modulation of the Wnt and BMP pathways to efficiently induce paraxial mesoderm from hPSCs. This is a prerequisite for the production of skeletal myogenic progenitors in large number. Other studies have shown that Wnt activation and BMP inhibition can produce mesodermal fates from human PSCs, such as Intermediate mesoderm ${ }^{29}$ and chondrogenic mesoderm ${ }^{30}$ which are closely related to the paraxial mesoderm. On the other hand, activation of BMP signaling has been used to produce anterior LPM derivatives such as cardiovascular cell types ${ }^{31-34}$. While little is known about the culture of early embryonic paraxial mesoderm from primary cultures ${ }^{35-38}$, myogenic progenitors and skeletal myoblast cultures have been extensively studied in vitro ${ }^{39-43}$.

The protocol described here stems from the transposition of a serum-free protocol developed for adherent mouse ESC culture to human pluripotent cell cultures ${ }^{1}$ (Figure1). At its core lays a dual modulation of Wnt and BMP pathways. It is based on our understanding of paraxial mesoderm development in vivo, where Wnt is activated to specify early paraxial mesoderm while BMP is inhibited to prevent the newly specified paraxial mesoderm cells to drift to a lateral plate fate ${ }^{22}$. In absence of BMP inhibition, Wnt activated- PSCs differentiate preferentially to LPM derivatives such as endothelial progenitors $^{44}$. For the hPSC protocol, the first step of the mESC protocol aiming at producing epiblast stage cells, was removed as hPSCs are more related to mouse EpiSCs $^{45}$. Fine-tuning of the factors' concentrations and exposure time was also necessary to obtain optimal paraxial mesoderm induction and subsequent skeletal myogenesis (Figure 2). Long term differentiated hPSC-culture ( $>1$ month) are very dense, produce abundant extracellular matrix (ECM), but retain Pax7+ myogenic progenitors. We noticed that dissociation and replating of these differentiated cultures led to a significant enrichment in myogenic cells (Figure 3 ). This step allows to produce 
in larger quantity more homogeneous myogenic cultures that are amenable for cryostorage or for diverse culture set-ups (Figure 4, 5).

Key advantages of the differentiation protocol reported here are the ease of implementation of a simple and robust 2D-culture system, higher yields, the production of both myogenic progenitors and mature fiber cell types, and a faster experimental timeline over existing protocols ${ }^{16,19,46-48}$. Unlike other protocols, this method does not require genetic manipulation such as forced expression of transcription factors ${ }^{49-53}$, nor resort on cell sorting strategies to purify the populations of interest ${ }^{17,54-57}$. Primary myoblast cultures obtained from biopsies and myogenic cell lines do not usually generate mature fibers but produce shorter, irregularly shaped myotubes lacking striation. In contrast, the protocol presented here describes how to generate in 30 days, striated millimeter-long skeletal muscle fibers in vitro, thus providing the relevant cell types to study both embryonic development and mature muscle diseases.

\section{Overview of the Procedure}

The starting material can be standard hESC or hiPSC culture ${ }^{58-62}$ (Figure 1a). Briefly, cells are dissociated to single cells and seeded at low density on Matrigel-coated wells. Cells are left to recover in maintenance conditions until they form small irregular aggregates, at which time (Day 0) they are changed to a sequence of differentiation media (Figure 1b). This sequence aims at first generating induced paraxial mesoderm progenitors (iPAMs) corresponding to the presomitic mesoderm stage in vivo, and then promoting their differentiation into skeletal muscles within 30 days (Figures 1, 2). In addition to myofibers, the hPSC-derived culture retains myogenic progenitors including Pax7+ satellite-like cells (Figure 2). These progenitors can be expanded to generate myogenic subcultures that can in turn be cryostored, redifferentiated (Figure 3,4 ) or used for various downstream applications (Figure 5).

\section{Applications of the protocol}


This protocol allows for the production of both myogenic progenitors, satellite-like cells and myofibers, which enable novel hPSC-based model to study important fundamental and applied skeletal muscle biology questions (Table 1 ). The expansion of hPSCmyogenic cultures is compatible with various experimental designs (Figure 5). Below we discuss the potential applications the different cell types generated by the protocol can be used for.

Paraxial mesoderm. The protocol described here provides a novel, tractable, in vitro system to study paraxial mesoderm formation (Figure 2). It is amenable for quantitative and real-time imaging and flow cytometry analysis. Important developmental biology questions related to paraxial mesoderm development can be investigated, including the specification of neuro-mesodermal progenitors, segmentation, somitogenesis, and lineage specification ${ }^{63,64}$. Combined with genetic manipulations, it allows to assess the role of individual genes in normal and pathological conditions. Production of hPSCderived myogenic progenitors may also be used as a more relevant and standardized source of cells for bioengineering approaches that have traditionally relied on cell lines and biopsies (Figure 5).

\begin{tabular}{|l|l|l|l|}
\hline & $\begin{array}{l}\text { Paraxial } \\
\text { mesoderm } \\
\text { Myogenic } \\
\text { progenitors }\end{array}$ & $\begin{array}{l}\text { Skeletal muscle } \\
\text { fibers } \\
\text { Myotubes }\end{array}$ & Satellite-like cells \\
\hline $\begin{array}{l}\text { Dev. Biology } \\
\text { in vitro model }\end{array}$ & Cell fate decision & Myogenesis \& & \begin{tabular}{l} 
Specification Niche \\
\hline $\begin{array}{l}\text { Cell biology } \\
\text { Physiology }\end{array}$
\end{tabular} \\
\hline Pathology & $\begin{array}{l}\text { Bioengineering } \\
\text { Tissue chips }\end{array}$ & $\begin{array}{l}\text { Electrophysiology } \\
\text { Coculture system } \\
\text { Musculoskeletal system, Myopathies }\end{array}$ & Homeostasis \\
\hline $\begin{array}{l}\text { Regenerative } \\
\text { medecine }\end{array}$ & $\begin{array}{l}\text { Bioengineering - Tissue repair - Drug } \\
\text { screening }\end{array}$ & $\begin{array}{l}\text { Cell therapy } \\
\text { Regeneration }\end{array}$ \\
\hline
\end{tabular}


Table (1) : Overview of the possible applications pertaining to hPSC-derived myogenic cultures. Columns represent distinct developmental /differentiation stages. Rows represent biomedical disciplines.

Myotubes and fibers. One of the main advantage of this protocol, is the production from hPSCs of both myogenic progenitors and millimeter-long, striated, often spontaneously contracting, skeletal myofibers (Figure 2, 4). Primary differentiation or secondary differentiation after subculturing allows production of myofibers on demand. This culture system allows also for the study of skeletal myogenesis including important events difficult to visualize in vivo such as myoblast fusion, satellite cell formation, myofibrillogenesis or fiber type specification. hPSC -derived myogenic cultures are a valuable alternative to primary myogenic cultures and immortalized cell lines. It is amenable for scale-up, or miniaturization for drug screening ${ }^{65}$, and can be combined with 3D bioengineered substrates (Figure 5a), tissue array/chip ${ }^{66,67}$ (Figure 5b) and complex electrophysiology or optogenetic time-lapse platforms ${ }^{68-78}$. Miniaturization is necessary for drug screening strategies aiming at identifying compounds able to promote progenitors' proliferation or fibers' maturation ${ }^{79,80}$. Furthermore, co-culture with other relevant cell types could allow the study of important aspects of muscle biology, namely the neuromuscular junction (motoneurons) ${ }^{81-89}$, the myotendinous junction (tenoblasts) $^{90,91}$, vascularization (endothelial cells) $)^{92-95}$ and metabolic coupling (adipocytes) ${ }^{96}$. Healthy cells can also be directly compared to cells harboring various mutations. In vitro models of human muscular dystrophies involving forced expression of myogenic factors such as Pax3/7 or MyoD in patients' induced PSCs to induce myogenesis have been reported, but the physiological relevance of the induced fibers remains to be established ${ }^{97-102}$. The protocol presented here recapitulates the developmental sequence of myogenic differentiation from hPSCs without introduction of exogenous genetic material and thus may provide more physiologically relevant models of these diseases. This may eventually allow the development of in vitro strategies for therapeutic approaches ${ }^{103-108}$. Muscle tissue engineering is a very active field, which has so far essentially relied on primary cultures derived from human or animal biopsies, and immortalized cell lines. Such applications will benefit from an unlimited and 
reproducible source of human myofibers and their progenitors, including satellite-like cells ${ }^{68,109-113}$.

Satellite-like cells. In adult muscle, quiescent stem cells (Pax7+ satellite cells) found in very small numbers in close association with muscle fibers allow for muscle repair during regeneration ${ }^{114,115}$. Elegant mouse genetics experiments have shown that satellite cells represent the key population allowing muscle regeneration in vivo ${ }^{116-}$ ${ }^{118}$.The transplantation of human skeletal myoblasts was shown to be inefficient as grafted cells massively die thus failing to engraft in the host ${ }^{119-122}$. In contrast, even minute numbers of satellite cells efficiently contribute to muscle regeneration in injured or dystrophic mouse muscles ${ }^{123-128}$. Thus, satellite cells represent the ideal candidate for cell therapy approaches aiming at reconstructing muscles. However, these cells are found in very limited number in adult muscles and they cannot be amplified in vitro as they lose their regenerative properties in culture ${ }^{123,129}$. Thus access to an unlimited source of satellite cells differentiated from pluripotent cell cultures could open the possibility to develop cell therapy protocols for muscular dystrophies. We have shown that the long term Pax7+ cells produced in vitro from mouse ES cells become tightly associated to differentiating fibers, locating under their basal lamina as expected for satellite cells. These Pax7+ cells can give rise to both muscle fibers and Pax7+ satellite cells when grafted in vivo suggesting that the Pax $7+$ cells differentiated in vitro correspond to satellite cells ${ }^{1}$. The muscle fibers differentiated in vitro from mouse ES cells exhibit characteristics of early post-natal fibers suggesting that the associated Pax7+ cells likely correspond to post-natal satellite cells. Remarkably, whereas adult satellite cells immediately become activated in vitro, losing the capacity to self-renew, immature satellite cells can still produce both Pax7+ satellite cells and myoblasts when cultured in vitro ${ }^{130}$. This property is shared by both mouse and human Pax7+ cells differentiated in vitro with our protocols. Furthermore, immature satellite cells were recently shown to exhibit remarkable regenerative properties which might be a significant advantage in the context of cell therapy protocols aiming at regenerating muscle ${ }^{130}$. We observed that the differentiation of human Pax7+ cells produced in vitro with our protocol is very similar to that of the mouse Pax7+ satellite-like cells and we anticipate that these cells also correspond to immature human satellite-like cells. 
Further analysis of the human Pax7+ cells produced with this protocol will be necessary to compare them to recently characterized human muscle stem cells ${ }^{128,131,132}$. In particular, the assessment of their regenerative properties in vivo will be key to be considered as a potential source of cells for cell therapy approaches ${ }^{133}$. These cultures could also permit to study the development of human satellite cells, a process on which nothing is currently known.

\section{Alternative Methodology}

Distinct methodologies have been used to produce skeletal muscle cells from hPSCs. In most cases, differentiation strategies have been first optimized on mouse embryonic stem cells (ESCs) before transposition to human PSCs (reviewed $\mathrm{in}^{119,134-141}$ ). Direct conversion methods consist of overexpressing myogenic factors in a stem cell to force it to differentiate into a myogenic progenitor, bypassing paraxial mesoderm specification ${ }^{142,143}$. The general concept of cell reprogramming by introduction of a factor was first demonstrated with the ability of MyoD to convert fibroblasts into myoblasts ${ }^{144}$. The method was perfected over time by the use of different vectors, including inducible systems to overexpress transcription factors- chiefly MyoD, Pax3 or Pax7 which can all elicit myogenic differentiation with various degrees of efficiency ${ }^{100,145-150}$. However, these methods require introduction of exogenous DNA into the cells, often via viral vectors, which is an issue for potential biomedical applications. Additionally, the molecular identity of the generated myogenic cell has not been investigated in great details. For MyoD conversion, myofiber maturation in vitro is usually improper due to incomplete myogenic activation and conversion ${ }^{143}$. The use of the upstream regulators, Pax3/7, although not restricted to the myogenic lineage ${ }^{151-155}$ allows for the production of in vitro myogenic progenitors ${ }^{146,150}$ that need to be further enriched by cell sorting. Recent work suggests that these induced myoblasts are able to generate striated fibers ${ }^{156}$. However, culture conditions are generally undefined, involving embryoid bodies formation and the use of serum. Other efforts have also 
aimed at generating other cell types found in the adult skeletal muscle, such as pericytes/mesoangioblasts which exhibit myogenic properties ${ }^{157-160}$.

\section{Limitations of the protocol}

Biological relevance. Very little is known about human paraxial mesoderm development due to the difficulty to access early human embryos. The protocol described here can provide a window in the development of this key lineage that not only gives rise to skeletal muscle but also to the axial skeleton and the dermis of the back. Access to an unlimited supply of genetically defined myogenic cells will allow the development of many biomedical applications to study muscle physiology and pathology. One major critique is the intrinsically artificial nature of the culture system which is vastly different compared to an organism in its full complexity ${ }^{161}$. Another relates to the differentiated cell types obtained in vitro, whose maturation is incomplete being closer to the early post-natal stage than to adult, which would be more desirable for relevant physiological and disease modeling investigations ${ }^{162}$. This might be overcome with more integrated cell culture systems, such as cocultures or "on-a-chip" design aiming at interconnecting tissues in a physiologically relevant manner ${ }^{76,81,88}$.

Research applications. Dense cell culture can render the optical analysis difficult if not unfeasible. Furthermore, primary differentiation is done typically on plastic cell culture dishes that might not be compatible with high-end imaging. However, we also successfully differentiated human muscle fibers from iPS cells on Thermanox coverslips. Subculturing can also circumvent both issues by allowing the control of seeding densities and cell culture format, allowing more flexible experimental setups (Figure 5). It is also well known that various hPSCs exhibit different propensity to differentiate toward one specific germ layer and tissue ${ }^{163,164}$. As such, it is expected that the nature of the starting cell lines will be a source of variability that can lead to a different level of myogenic differentiation. We believe we provide a robust conceptual framework based on developmental principles that is amenable to most cell lines with limited adaptations. In our hands, we have routinely achieved efficient differentiation of 
about $\sim 8$ independent lines including hiPS11a (HSCl, Harvard University), NCRM1 and NCRM5 (RUCDR, Rutgers University), H9 (WiCell, Madison, WI) and HUES1 (HSCl, Harvard University).

Biomedical applications. All cell material and reagents will need to meet safety and regulations approval by Regulatory agencies if the cell populations are to be used in clinical trials and in a regenerative/cell therapy context ${ }^{165}$. However, we expect that the first biomedical applications of PSCs differentiated in vitro will be in the domain of high throughput screening, in vitro disease modeling and cell toxicity assays ${ }^{65,76,166}$, for which such approval is not required.

\section{Experimental design}

hPSCs lines. Quality of the starting hPSC line is essential (Figure 1a). Cell lines should be karyotypically normal, pathogen -free and pluripotent. hPSC cell lines should come from recognized cell repositories. hPSCs can be maintained by a variety of methods ${ }^{58,59}$. Regular monitoring and characterization of hPSC culture is essential. Large archive and working banks should be done at low passages.

Mycoplasma detection can be performed using PCR-based detection method such as the Venor GeM Mycoplasma Detection Kit. Complementary ways to assess the hPSC status include evaluation of colony growth, immunohistochemistry or Fluorescenceactivated flow cytometry (FACS) analysis for stem cell markers expression, embryoid bodies formation and histological analysis of hPSCs-derived teratoma ${ }^{60}$. All cell lines used in this study come from recognized repositories and are mycoplasma-free.

Cell culture reagents. Key reagents, including the Knockout Serum Replacement, chemical compounds, and recombinant proteins should be systematically tested. In particular, reagents' providers and production lots should be recorded. Due to variations in manufactured biologics, different lots should be tested in parallel and 
benchmarked against previous references on side-by-side differentiations to ensure an optimal experimental outcome.

Culture format. The protocol was originally developed for standard 2D adherent cell culture, in 24- to 6-well plates. While the step-by-step procedure provided below is optimized for a 12-well plate format, transposition to 24-, or 6- well plate formats is straightforward by respecting the corresponding surface ratio and volumes. It is possible also to further scale up or down by seeding on other types of plates (see for example ${ }^{167}$ ). We successfully differentiated cells in 96-well plate and in P10 cm dish format.

Culture density. Both the cell seeding density and the culture's confluency at Day 0 are critical for the success of differentiation. Seeding density should be within 15,000 and 45,000 cells $/ \mathrm{cm}^{2}$ (it can be lower for larger surface area). After 1 to 2 days of recovery in medium containing the anti-apoptotic ROCK inhibitor ${ }^{168}, 10-25 \%$ confluent homogenous cultures can be used for directed differentiation. Deviation from these guidelines leads usually to failure of differentiation either due to cell death or to overcrowding and culture detachment en masse.

Culture substrate. The default substrate is Matrigel (Corning; see also ${ }^{169}$ ) which is compatible with robust cell attachment and myogenic differentiation. More defined substrates such as Gelatin, or specific recombinant laminin and fibronectin -coating have been used in the past for myogenic progenitors ${ }^{170-173}$, however we observed that maturing myogenic culture were more susceptible to detach on those substrates.

Subculturing step. During differentiation, cultures become confluent within a week. After 30-40 days (Figure 1c), they are very dense and tend to detach from the substrate as sheets of cells, possibly due to myofibers' spontaneous contractions. We found that replating and splitting of these original cultures leads to a significant enrichment in myogenic cells and to less dense cultures easier to image (Figure 3,5). Passaging can be performed by combined mechanical and enzymatic dissociation of 10 to 50+ day-old culture with 25-45 days being the optimal window (Figure 3). Because of extensive extracellular ECM deposition, older cultures are harder to dissociate properly 
without causing significant cell death. Optimal reseeding density corresponds to a splitting ratio of $1: 4$ to $1: 8$; or about $60-70,000 \mathrm{cells} / \mathrm{cm}^{2}$. Subculturing results in selection of myogenic progenitors while depleting unwanted differentiated contaminants and accumulated culture debris. While post-mitotic cells (myocytes and myofibers) are essentially lost by the subculture step, myogenic precursors are preserved and can be amplified with commercially-available growth media used for primary muscle cultures and cell lines (compare Figure $1 c$ and $3 d$ ). For this purpose, we used the Skeletal Muscle Cell Growth Media-2 (Clonetics, Lonza; see Media composition). De novo myofibers can be produced again by differentiation of the subculture (Figure 3-5). Furthermore, confluent cultures left in proliferative media are fairly stable and retain a pool of Pax7-myogenic progenitors for months, which can be used later for downstream applications (Figure 3-5). The subculture is thus amenable for further passaging, cryostorage, and/or secondary differentiation (Figure 3).

Myogenic Differentiation media. Secondary differentiation can be achieved either by transferring to "terminal differentiation" media such as horse serum containing media $^{40}$, or serum-free media containing insulin and the N2 supplement ${ }^{57,174-176}$ (Figure $3-5)$.

Differentiation yield. Both the total number and the percentage of target cell type should be quantified to assess protocol efficacy and reproducibility, and possible troubleshooting. The protocol was designed as a multistep protocol with a sequence of defined media and developmental milestones. Proper differentiation should be assessed regularly. This is particularly important when working with novel hPSC lines or several lines for side-by-side comparison. We favor immunohistochemistry for specific validated markers to evaluate differentiation efficiency (Figures 2, 4; Table 2). Paraxial mesoderm progenitors' specification can be monitored with antibodies against $\mathrm{T} /$ Brachyury, or $\mathrm{Tbx}^{10,177,178}$. It should be kept in mind that most markers are not entirely specific to the target tissue along the whole developmental spectrum (see Table 2). We found that Msgn1 $1^{179,180}$ is the most reliable and specific marker of paraxial mesoderm progenitors. While, unfortunately, no validated Msgn1 antibody is currently available, Msgn1 expression can be monitored by RT-qPCR or using reporter cell lines (data not 
shown). Like Tbx6, Msgn1 expression is expected to peak around day 4-5 of differentiation with this protocol, accounting for $70-90 \%$ of the cells. Myogenesis per se should be monitored starting on week 2 by following MyoD and Myogenin expression ${ }^{181-}$ 183, while myotubes formation and fiber maturation can be assessed using skeletal muscle proteins or isoforms, such as Myosin Heavy chains ${ }^{184}$ (Figure 2, Table 2). The presence of satellite-like cells in long term culture can be evaluated with the expression of $\operatorname{Pax}^{185,186}$ (Figure 2b, 4a,b). By 4 weeks ( d 30 ) of differentiation, about $22 \%$ of nuclei are Myogenin-positive while another $23 \%$ are Pax7-positive ${ }^{1}$. Upon subculturing and 2 more weeks of differentiation of 3 independent cell lines, up to $40 \%$ of total nuclei were Myogenin -positive (Figure $5 \mathrm{~d}$ ). Mature skeletal myofiber density was ranging from 9,000 to 20,000 fibers per $\mathrm{cm}^{2}$ (Figure $5 \mathrm{c}$ and data not shown).

Level of expertise to implement the protocol. Prior experience with routine human PSC culture and cellular phenotyping is valuable, especially to scale the culture up or down, and to adapt the protocol to specific applications. Familiarity with the concept of directed differentiation can be advantageous for protocol troubleshooting. 


\section{MATERIALS \\ REAGENTS \\ Cells}

- Human Pluripotent Stem cells, we have successfully used the following: hiPSCs: hiPS11a (HSCl, Harvard University), NCRM1, NCRM5 (RUCDR, Rutgers University) hESCs: H9 (WiCell, Madison, WI), HUES1 (HSCl, Cambridge, MA)

CAUTION Cell line identity should be regularly verified and cultures tested for mycoplasma contamination. Experiments involving human pluripotent stem cells must conform to relevant Institutional and National regulations, we gained ethical approval from IACUC /ESCRO 2014-06-02 CRITICAL Different cell lines may respond to directed differentiation with variable level of myogenic differentation.

\section{Media}

- mTeSR1 (Stemcell Technologies, cat. no. 05851)

- DMEM/F12 1:1 (Life Technologies, cat. no. 11320-082)

- Knockout Serum Replacement (KSR; Life Technologies, cat. no.10828-028)

CRITICAL Lot-to-lot variability may impair the differentiation protocol

- L-Glutamine- Penicillin-streptomycin (Gibco, cat. no. 10378-016)

-2-Mercaptoethanol, 55mM (BME; Life Technologies, cat. no.21985-023)

- Non-essential amino acid solution [NEAA] (Thermo Fisher, cat. no. 11140-050)

- Insulin-Transferrin-Selenium (ITS; Life Technologies, cat. no. 41400-045)

- BSA (Sigma, cat. no. A7906)

- N-2 Supplement (Life Technologies, cat. no.17502-048)

- Horse serum (Invitrogen, cat. no. 16050-130)

- SkGM-2 (SkGM; Lonza, cat. no. CC-3245)

- Cryostem Freezing medium (Stemgent, cat.no.01-0013-50)

\section{Cell culture reagents}

- Dulbecco's Phosphate Buffered Saline (DPBS), calcium/magnesium free (Gibco, cat. no.14190-144)

-Tris Buffered Saline (TBS), 10X (Sigma, cat.no.T5912-1L)

- Sterile cell culture-grade water (Invitrogen, cat. no. 10977-015)

- Matrigel, hESC-qualified (MG; Corning, cat. no. 35277) 
- Gelatin solution EmbryoMax 0.1\% (wt/vol) (EMD Millipore, cat. no. es-006-b)

- Trypsin EDTA 0.25 M, pH 8.0 (Life Technologies, cat. no. 25200-056)

- TrypLE Express (Invitrogen, cat. no. 12605010)

- Dispase (1U/mL) (Stem cell technologies, cat.no.07923)

- Collagenase type I (Thermo Fisher, cat. no. 17100-017)

- DMSO, Cell culture grade (Sigma, cat. no. D2650)

- Trypan Blue solution 0.4\%, Cell culture grade (Sigma, cat.no.T8154-20ML)

\section{Factors}

- CHIR99021 (Tocris Bioscience, cat. no. 4423)

CRITICAL GSK3 beta inhibitors other than CHIR may not be as efficient

- LDN-193189 (Stemgent, cat. no. 04-0074)

CRITICAL BMP type I receptor inhibitors other than LDN may not be as efficient

- Y-27362 Dihydrochloride (Rocki; Tocris Bioscience, cat. no. 1254)

- HGF, Recombinant Murine (PeproTech, cat. no. 315-23)

- FGF2, Recombinant Murine (PeproTech, cat. no. 450-33)

- IGF1, Recombinant Murine (Peprotech, cat. no. 250-19)

- Paraformaldehyde (Electron Microscopy Sciences, cat. no. 15710)

CAUTION Paraformaldehyde must be handled under a chemical cabinet.

- Triton X-100 (Sigma-Aldrich, cat. no. T8787-250ML)

- Tween-20 (Sigma-Aldrich, cat. no. P7949-500ML)

- Fetal Bovine Serum (FBS; Hyclone/GE, cat. no. SH30070.03)

- Hoechst 33342 (Life Technologies, cat. no. H3570)

- Primary antibodies (see Table 1)

- Secondary antibodies, species specific anti-lgG(H+L) - Alexa fluor conjugated (Molecular probe)

- Isopropanol, 70\% (VWR, cat. no. 89499-420)

- Venor GeM Mycoplasma Detection Kit, PCR-based (Minerva Biolabs, Sigma cat. no. MP0025-1KT)

\section{- EQUIPMENT}

- Cell culture multiwell-plates (VWR, cat. nos. 353046; 353043; 353047) 
- Cell culture dishes (Corning, cat. nos. 353001; 353002)

- Cryovials (Nalgene, cat. no. 5000.0020)

- Needles, 25G (Becton Dickinson, cat. no. 305125)

- Sterile cell scrapers (Celltreat, cat. no. 229306)

- Sterile plastic tubes, $15 \mathrm{ml} \& 50 \mathrm{~mL}$ (VWR, cat. nos. 89039-66; 8939-658)

- Test tubes, $5 \mathrm{~mL}$ round bottom, snap cap (Corning, cat. no.352063)

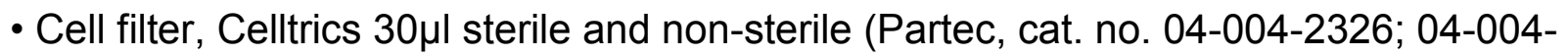
2316)

- Sterile plastic pipettes (Corning, cat. nos. 356543; 356551; 356525)

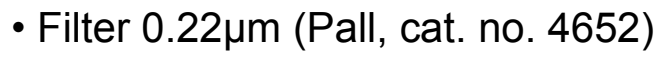

- Cell strainer 70 $\mu \mathrm{m}$ (ThermoFisher, cat. no. 22363548)

- Pipettes Filtered tips (VWR, cat.nos. 89003-060; -056; -048; 89368-974)

- Freezing container (Biocision, cat. no. BCS-405G)

- Filter for vacuum system $0.2 \mu \mathrm{m}$ hydrophobic (Pall, cat. no. 4251)

- Pasteur pipettes (VWR, cat.no. 14673-010)

- Water purification system (EMD Millipore, cat.no. SYNSVROWW)

- Cell counter (Nexcelom Bioscience, cat. no. Auto2000)

- Pipette-aid Easypet 3 (Eppendorf, cat. no. 4430000018)

- Pipettes Research plus 4-pack (Eppendorf, cat. no. 022575442)

- Centrifuge 5810 w rotor A-4-62 (Eppendorf, cat. no. 022627007)

- Biosafety cabinet HERAsafe KS Type KS12 (Thermo Scientific, cat. no. 51022482)

-Vacuum filtering units, M-Vac (Argos Technologies; cat. no. VWR \# 89129-568)

- Incubator CO2 Incubator (Panasonic, cat. no. KM-CC17RUI)

- Digital Microscope EVOS XL Imaging System (Life Technologies, cat. no. AME3300)

- Digital Fluorescence Microscope EVOS FL Imaging System (Life Technologies, cat. no. AMF4300)

- Picking station, Lynx Stereo Dynascopic Microscope (Vision Engineering, cat. no. Lynx)

- Freezer -80C, Ultra-low Temp Freezer (Panasonic,cat. no. MDF-U53VA)

- Liquid nitrogen storage tank (Cryosafe, cat. no. T CAT 7PS )

- Water bath (VWR, cat.no.89032-200) 


\section{- REAGENT SET UP}

- Recombinant Factors stock solution (FGF2, HGF, IGF1) Resuspend the lyophilisate in sterile cell culture-grade PBS supplemented with $0.1 \%$ BSA to desired stock concentration. Aliquot in $50 \mu \mathrm{L}$ volume and store at $-20{ }^{\circ} \mathrm{C}$ for up to 6 months. FGF2 stock solution $10 \mu \mathrm{g} / \mathrm{ml}$, use at $20 \mathrm{ng} / \mathrm{ml}$; HGF stock concentration $100 \mu \mathrm{g} / \mathrm{ml}$, use at $10 \mathrm{ng} / \mathrm{ml}$; IGF stock concentration $10 \mu \mathrm{g} / \mathrm{ml}$, use at $2 \mathrm{ng} / \mathrm{ml}$.

\section{- Chemical compounds stock solution (CHIRON99021, LDN-193189, Y27362)}

Resuspend the lyophilisate in cell culture grade DMSO (CHIRON, LDN-193189) or $\mathrm{H}_{2} \mathrm{O}$ (Y27362) to desired concentration. Aliquot in $50 \mu \mathrm{L}$ volume and store at $-20^{\circ} \mathrm{C}$ for up to

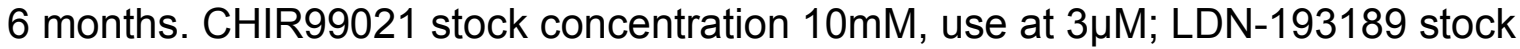
concentration 1mM, use at 500nM; Y27362 (Rock inhibitor) stock concentration 10mM, use at $10 \mu \mathrm{M}$.

- Matrigel and Matrigel -coated plates Thaw the stock solution overnight on ice at $4^{\circ} \mathrm{C}$, and once it is in

liquid form keep it on ice and divide the solution into aliquots (lot-specific volume by manufacturer's recommendation) using cold tips and cold tubes. Store at $-80^{\circ} \mathrm{C}$. When needed, thaw aliquots on ice, dilute with $12 \mathrm{ml}$ ice cold DMEM/F12 resulting in $3 \mathrm{mg} / \mathrm{ml}$ protein concentration and mix by pipetting. Add $1 \mathrm{ml}$ of diluted Matrigel solution per $10 \mathrm{~cm}^{2}$ of multiwell plates or dishes to cover surface evenly. Keep on ice for at least $4 \mathrm{~h}$ and prior to use incubate at $37^{\circ} \mathrm{C}$ for $30 \mathrm{~min}$. Store Matrigel coated plates at $4{ }^{\circ} \mathrm{C}$ for up to 2 weeks.

CRITICAL Matrigel solidifies above $4^{\circ} \mathrm{C}$ so ensure all the cell culture plastic is ice cold during handling.

- mTeSR medium. Thaw $100 \mathrm{~mL}$ bottle of $5 x$ Supplement overnight at $4^{\circ} \mathrm{C}$ and add it to the mTeSR- medium. Mix and divide into $40 \mathrm{~mL}$ aliquots. Store at $-20^{\circ} \mathrm{C}$ for up to 3 months. Upon use, thaw an aliquot at room temperature and keep at $4^{\circ} \mathrm{C}$ for up to 2 weeks.

- SkGM-2 medium. Supplement SkGM basal medium by adding the components of SkGM Bulletkit. Mix and aliquot in $50 \mathrm{~mL}$ tubes. Store at $-20^{\circ} \mathrm{C}$ for up to 3 months. Upon use, thaw an aliquot and keep at $4^{\circ} \mathrm{C}$ for up to 2 weeks.

- Paraformaldehyde. Dilute the $16 \%$ glass sealed EM-grade Paraformaldehyde stock in DPBS. Leftover $16 \%$ stock solution can be frozen for later use. $2-4 \%$ working solution should be prepared fresh extemporaneously.

CAUTION: Paraformaldehyde is toxic and must be manipulated under a chemical cabinet. Used solution should be disposed according to local institutional guidelines.

- TBST Buffer. Dilute the Tris-Buffered Saline (TBS) 10X buffer with ultrapure water, and supplement with $0.1 \%(\mathrm{vol} / \mathrm{vol})$ Tween-20. Store at room temperature (RT, 15$25^{\circ} \mathrm{C}$ ) for up to 3 weeks. 
- Blocking Reagent. Dilute the TBS 10X buffer with ultrapure water, and supplement with $1 \%(\mathrm{vol} / \mathrm{vol}) \mathrm{FBS}$, and $0.1 \%(\mathrm{vol} / \mathrm{vol})$ Triton-X100. Keep at $4^{\circ} \mathrm{C}$ for up to 2 weeks. 
- Differentiation media.

Prepare cell media according to the table below and filter on $0.22 \mu \mathrm{m}$ mesh. Small compounds and recombinant proteins should be added extemporaneously but base media can be stored at $4{ }^{\circ} \mathrm{C}$ for up to 2 weeks.

Small compounds and recombinant proteins (in italic in the tables) should be added immediately before use.

\section{Di-CL /Di-CLF Media}

\begin{tabular}{|l|l|l|}
\hline Composition & Volume (250mL) & Final concentration \\
\hline DMEM/F12 & $244.5 \mathrm{~mL}$ & \\
\hline ITS & $2.5 \mathrm{~mL}$ & $1 \%(\mathrm{vol} / \mathrm{vol})$ \\
\hline $\begin{array}{l}\text { Non-essential amino } \\
\text { acids }\end{array}$ & $2.5 \mathrm{~mL}$ & $1 \%(\mathrm{vol} / \mathrm{vol})$ \\
\hline Penicillin / Streptomycin & $0.5 \mathrm{~mL}$ & $\begin{array}{l}0.2 \%(\mathrm{vol} / \mathrm{vol})(20 \mathrm{IU}+0.02 \\
\mathrm{mg}) / \mathrm{ml}\end{array}$ \\
\hline CHIR-99021 & $75 \mu \mathrm{L}$ & $3 \mu \mathrm{M}$ \\
\hline LDN-193189 & $125 \mu \mathrm{L}$ & $0.5 \mu \mathrm{M}$ \\
\hline Recombinant FGF-2 & $500 \mu \mathrm{L}$ & $20 \mathrm{ng} / \mathrm{mL}$ \\
\hline
\end{tabular}

DK-HIFL Media

\begin{tabular}{|l|l|l|}
\hline Composition & Volume (250mL) & Final concentration \\
\hline DMEM/F12 & $209.5 \mathrm{~mL}$ & \\
\hline KSR & $37.5 \mathrm{~mL}$ & $15 \%(\mathrm{vol} / \mathrm{vol})$ \\
\hline $\begin{array}{l}\text { Non-essential amino } \\
\text { acids }\end{array}$ & $2.5 \mathrm{~mL}$ & $1 \%(\mathrm{vol} / \mathrm{vol})$ \\
\hline Penicillin / Streptomycin & $0.5 \mathrm{~mL}$ & $0.2 \%(\mathrm{vol} / \mathrm{vol})$ \\
\hline 2-Mercaptoethanol & $454 \mu \mathrm{L}$ & $0.1 \mathrm{mM}$ \\
\hline Recombinant HGF & $25 \mu \mathrm{L}$ & $10 \mathrm{ng} / \mathrm{mL}$ \\
\hline Recombinant IGF-1 & $50 \mu \mathrm{L}$ & $2 \mathrm{ng} / \mathrm{mL}$ \\
\hline Recombinant FGF-2 & $500 \mu \mathrm{L}$ & $20 \mathrm{ng} / \mathrm{mL}$ \\
\hline LDN-193189 & $125 \mu \mathrm{L}$ & $0.5 \mu \mathrm{M}$ \\
\hline
\end{tabular}

DK-I / DK-HI Media

\begin{tabular}{|l|l|l|}
\hline Composition & Volume (250mL) & Final concentration \\
\hline DMEM/F12 & $209.5 \mathrm{~mL}$ & \\
\hline KSR & $37.5 \mathrm{~mL}$ & $15 \%(\mathrm{vol} / \mathrm{vol})$ \\
\hline $\begin{array}{l}\text { Non-essential amino } \\
\text { acids }\end{array}$ & $2.5 \mathrm{~mL}$ & $1 \%(\mathrm{vol} / \mathrm{vol})$ \\
\hline Penicillin / Streptomycin & $0.5 \mathrm{~mL}$ & $0.2 \%(\mathrm{vol} / \mathrm{vol})$ \\
\hline 2-Mercaptoethanol & $454 \mu \mathrm{L}$ & $0.1 \mathrm{mM}$ \\
\hline Recombinant HGF & $25 \mu \mathrm{L}$ & $10 \mathrm{ng} / \mathrm{mL}$ \\
\hline Recombinant IGF-1 & $50 \mu \mathrm{L}$ & $2 \mathrm{ng} / \mathrm{mL}$ \\
\hline
\end{tabular}




N2 Media
\begin{tabular}{|l|l|l|}
\hline Composition & Volume $(\mathbf{2 5 0 m L})$ & Final concentration \\
\hline DMEM/F12 & $242 \mathrm{~mL}$ & \\
\hline ITS & $2.5 \mathrm{~mL}$ & $1 \%(\mathrm{vol} / \mathrm{vol})$ \\
\hline N2 supplement & $2.5 \mathrm{~mL}$ & $1 \%(\mathrm{vol} / \mathrm{vol})$ \\
\hline Penicillin / Streptomycin & $0.5 \mathrm{~mL}$ & $0.2 \%(\mathrm{vol} / \mathrm{vol})$ \\
\hline L-glutamine & $2.5 \mathrm{ml}$ & $1 \%(\mathrm{vol} / \mathrm{vol})$ \\
\hline
\end{tabular}


- PROCEDURE

Pluripotent cell culture preparation • TIMING 5 - 7 d

1| Pluripotent cell culture maintenance and amplification. Culture hPSCs colonies on $35 \mathrm{~mm}$ Matrigel coated dishes. Passage when culture reaches $\sim 70 \%$ confluency (Figure 1a).

2| Prepare new $35 \mathrm{~mm}$ dishes to passage colonies: pre incubate Matrigel coated dishes at $37^{\circ} \mathrm{C}$ for $30 \mathrm{~min}$. Just prior to passaging replace Matrigel with $2 \mathrm{~mL}$ of room temperature $\mathrm{mTeSR}$.

3| Passage cells either by the cutting method (option A) or by the Dispase method (option B).

CRITICAL STEP While any hPSC lines can be passaged by cutting method, allowing the selection of the optimal colonies, the Dispase method allows for easier bulk passaging, however it should be performed only on cultures with low overall spontaneous differentiation. Some hPSC line are more prone to culture failure (cell death, differentiation) with Dispase method.

Option A- Cutting method

1. Using a 25 gauge needle tip, cut healthy hPSC colonies into small pieces using an "eyepiece-less" stereo microscope (Lynx).

CRITICAL STEP Colony pieces should not be too small or too big, approximately $200 \mathrm{x}$ $200 \mu \mathrm{m}$ use the width of the needle as a size proxy (Figure 1a).

2. Scrape and collect colony pieces using a $20 \mu \mathrm{L}$ Pipette. Gently aspirate while detaching the pieces from cell culture dish with the pipette tip.

Option B- Dispase method

1. Discard medium, rince dish with PBS, add $1 \mathrm{~mL}$ of dispase $(1 \mathrm{U} / \mathrm{ml})$ to the dish and incubate $5 \mathrm{~min}$ at $37^{\circ} \mathrm{C}, 5 \% \mathrm{CO} 2$, for 5-7 min.

CRITICAL STEP Differentiated colonies should be scraped away beforehand.

2. Remove the dispase solution, rince dish twice with PBS, add $1 \mathrm{ml}$ of $\mathrm{mTeSR}$ and detach the colonies using a cell scraper.

3. Triturate detached colonies to fragment them to suitable size.

\section{CRITICAL STEP}

Colony pieces should not be too small or too big, approximately $200 \times 200 \mu \mathrm{m}$, usually achieved by pipetting up and down 2-3 times using a $1000 \mu \mathrm{L}$ pipette

4| Transfer 50-100 colony pieces/ fragments onto the new Matrigel-coated dishes (step

2) and distribute fragments evenly by gently rocking the plate back and forth, and side to side (Figure 1a). Place in incubator at $37^{\circ} \mathrm{C}, 5 \% \mathrm{CO} 2$.

CAUTION: Some hPSC lines are better maintained under controlled $4 \% \mathrm{O}_{2}$. 


\section{Predifferentiation setup (Day-2) • TIMING 2 d}

5| Single-cell dissociation of PSCs culture. Change mTeSR medium every day until hPSC cultures reach confluency of $\sim 70 \%$.

CRITICAL STEP Starting hPSC culture must consist of homogeneous and healthy looking colonies.

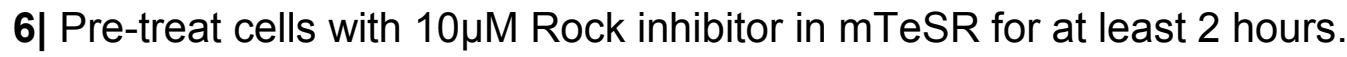

7| Prepare 12-well plates coated with Matrigel.

CRITICAL STEP This procedure can be easily performed with 24- and 6-well plate by adapting volume and cell numbers to the surface ratio.

8| Rinse hPSC culture with DPBS without Calcium and Magnesium.

9| Add $100 \mu \mathrm{l} / \mathrm{cm}^{2}$ of TrypLE Express and incubate at $37^{\circ} \mathrm{C}, 5 \% \mathrm{CO}$, for 5-7 min.

10| Observe cell dissociation under microscope and help mechanical dissociation by tapping the plate.

Most of the colonies will dissociate to a suspension of single cells or small loose, irregular aggregates.

11 Collect cell suspension in a $15 \mathrm{ml}$ sterile tube and gently further triturate with a $1000 \mu \mathrm{L}$ pipette.

12| Add 10ml of DMEM/F12 to inactivate TrypLE Express.

13 | Centrifuge cells at $300 \mathrm{~g}$ for $5 \mathrm{~min}$.

14| Remove supernatant and resuspend the pellet gently in $1 \mathrm{ml}$ of $\mathrm{mTeSR}+10 \mu \mathrm{M}$ Rocki.

15| Count the cells and use Trypan Blue or similar to assess cell viability.

16| Dilute cells in mTeSR $+10 \mu \mathrm{M}$ Rocki so as to plate them at $3 \times 10^{4}$ cells per $\mathrm{cm}^{2}$ ( ie. $1.2 \times 10^{5}$ cells in $1.5 \mathrm{~mL}$ of medium for 1 well of a 12 -well plate).

17| Rinse the Matrigel-coated differentiation plates with PBS and plate cells at $3 \times$ $10^{4}$ cells per $\mathrm{cm}^{2}$ in $\mathrm{mTeSR}+10 \mu \mathrm{M}$ Rocki. (one p35 dish can typically produce enough cells for a whole 12 -well plate)

Distribute cells by rocking the plate gently four times back and forth, side to side. 
CRITICAL STEP Even distribution of the cells is critical to create homogenous differentiation conditions. Cells plated on 24-well plate and smaller tend to clump on the edges and in the center of the well if not properly distributed. Cell density and plating efficiency are crucial for the survival of the culture. Too sparse plating leads to detachment of the colony within the first five days, and too dense culture will quickly become over-confluent and result in heterogeneous differentiation of the culture.

18| Incubate the plate at $37^{\circ} \mathrm{C}, 5 \% \mathrm{CO} 2$, overnight.

19| Observe the cells and change mTeSR daily until hPSCs cultures reach a confluency of $\sim 15-20 \%$.

During Rocki treatement, cells at low density to adopt a spiky morphology. Cultures will have many small $(30<$ cells) colonies which is optimal to start differentiation (usually after 1-2 days) (Figure 1c).

CRITICAL STEP Small colonies should be evenly distributed on the dish surface optimal for optimal differentiation.

TROUBLESHOOTING

\section{Directed Differentiation (Day 0-40) - TIMING 30 - $40 \mathrm{~d}$}

20|Day 0. Once cultures have reached $15-20 \%$ confluency, change the medium to DiCL (Dmem-ITS-Chir-Ldn) medium to initiate differentiation. This is Day 0 of differentiation. Refresh media daily until Day 3 (Figure $1 b, c$ ).

21| Day3. Change medium to DiCLF (Dmem-ITS-Chir-Ldn-Fgf) medium and refresh daily until Day 6.

Ideally, medium should be changed daily until Day 12 of differentiation. However, one day (weekend) can be omitted while respecting the different media sequence.

22| Day 6, change medium to D-KHIFL (Dmem-KSR-Hgf-Igf-Fgf-Ldn) and refresh daily until Day 8.

CRITICAL STEP Significant cell death will be observed the first week, this is normal selective action of the sequence of media.

23| Day 8, change medium to D-KI (Dmem-KSR-lgf) and refresh daily until Day 12. TROUBLESHOOTING

24| Day 12, change medium to D-KHI (Dmem-KSR-Hgf-Igf) and refresh every other day thereafter (Figure 1b).

CRITICAL STEP Media change over the weekend can be avoided by doubling the culture media volume beforehand.

25| Observe the cultures for myotube formation and change the differentiation medium every other day. Myotubes are usually visible after 30 days of differentiation (Figure 1c, $2 b)$

CRITICAL STEP Differentiated cultures are delicate, as myotubes detach easily. Medium change should be done slowly to avoid cell detachment. 


\section{TROUBLESHOOTING}

\section{Culture characterization $\bullet$ TIMING 2-4d}

26| Wash twice with DPBS cultures obtained either through primary differentiation ( steps 20-25) or through differentiation of subcultures (steps 37-54)

27| Fix cultures plates with $250 \mu \mathrm{L} / \mathrm{cm}^{2}$ of $2 \%$ (vol/vol) paraformaldehyde for $10 \mathrm{~min}$ at $\mathrm{RT}$ or $\mathrm{O} / \mathrm{N}$ at $4^{\circ} \mathrm{C}$.

CRITICAL STEP Paraformaldehyde must be handled under a chemical cabinet.

28| Rinse cells with DPBS.

PAUSE POINT Fixed cells can be kept in DPBS at $4^{\circ} \mathrm{C}$ for at least 2 weeks before proceeding with the staining.

29| Permeabilize the cells by adding $250 \mu \mathrm{L} / \mathrm{cm}^{2}$ of TBST buffer, at RT, for $3 \mathrm{~min}$. Repeat three times.

$30 \mid$ Incubate cells in Blocking solution at $250 \mu \mathrm{L} / \mathrm{cm}^{2}$ for $30 \mathrm{~min}$ at RT.

31| Incubate cells in primary antibodies diluted in Blocking solution overnight at $4^{\circ} \mathrm{C}$ on a shaker. See Table 1 for a list of antibodies we have successfully used.

CRITICAL STEP When working with novel/not validated antibodies, specificity and optimal dilution of the antibody should be evaluated separately.

\begin{tabular}{|l|l|l|l|l|}
\hline Marker & $\begin{array}{l}\text { Temporal } \\
\text { Expression }\end{array}$ & $\begin{array}{l}\text { Antibody } \\
\text { Reference }\end{array}$ & $\begin{array}{l}\text { Working } \\
\text { dilution }\end{array}$ & $\begin{array}{l}\text { Differentiation } \\
\text { specificity } \\
\text { (and other tissues marked) }\end{array}$ \\
\hline $\begin{array}{l}\text { T/ } \\
\text { Brachyury }\end{array}$ & $\sim \mathrm{d} 2$ & $\begin{array}{l}\text { R\&D } \\
\text { cat. no. } \\
\text { AF2085 }\end{array}$ & $1: 250$ & $\begin{array}{l}\text { Early mesoderm } \\
\text { (notochord) }\end{array}$ \\
\hline Tbx6 & $\sim \mathrm{d} 4$ & $\begin{array}{l}\text { Abcam } \\
\text { cat.no. } \\
\text { ab38883 }\end{array}$ & $1: 200$ & Early mesoderm, PSM \\
\hline Pax3 & $\sim \mathrm{d} 5-15$ & $\begin{array}{l}\text { DSHB } \\
\text { cat.no. Pax3-c }\end{array}$ & $1: 250$ & $\begin{array}{l}\text { Anterior PSM, Dermomyotome } \\
\text { (neural tube, neural crest) }\end{array}$ \\
\hline MyoD & $\sim$ d15+ & $\begin{array}{l}\text { Santa cruz } \\
\text { Clone 5.8A } \\
\text { cat.no. sc- } \\
32738\end{array}$ & $1: 200$ & Myoblasts, myotubes \\
\hline Pax7 & $\sim$ d25+ & $\begin{array}{l}\text { DSHB } \\
\text { cat.no. Pax7-c }\end{array}$ & $1: 250$ & $\begin{array}{l}\text { Pre-Myoblasts, } \\
\text { Satellite-like cells }\end{array}$ \\
\hline
\end{tabular}




\begin{tabular}{|l|l|l|l|l|}
\hline $\begin{array}{l}\text { Myogenin } \\
\text { (Myog) }\end{array}$ & $\sim \mathrm{d} 25+$ & $\begin{array}{l}\text { DSHB } \\
\text { cat.no. F5-c }\end{array}$ & $1: 250$ & $\begin{array}{l}\text { Myocytes, myotubes and } \\
\text { myofibers }\end{array}$ \\
\hline $\begin{array}{l}\text { Myogenin } \\
\text { (Myog) }\end{array}$ & $\sim \mathrm{d} 25+$ & $\begin{array}{l}\text { Santa cruz } \\
\text { cat.no. sc- } \\
576 \mathrm{x}\end{array}$ & $1: 800$ & $\begin{array}{l}\text { Myocytes, myotubes and } \\
\text { myofibers } \\
\text { (leaky staining in sarcoplasm, } \\
\text { use at 1:800+) }\end{array}$ \\
\hline $\begin{array}{l}\text { Myosin } \\
\text { Heavy } \\
\text { Chain } \\
\text { (MyHC) }\end{array}$ & $\sim \mathrm{d} 25+$ & $\begin{array}{l}\text { DSHB } \\
\text { cat.no. MF20-c }\end{array}$ & $1: 300$ & $\begin{array}{l}\text { Myocytes, myotubes and } \\
\text { skeletal myofibers } \\
\text { (Cardiomyocytes) }\end{array}$ \\
\hline $\begin{array}{l}\text { Myosin } \\
\text { Heavy } \\
\text { Chain Fast } \\
\text { perinatal/ } \\
\text { (Fast } \\
\text { MyHC) }\end{array}$ & $\sim \mathrm{d} 25+$ & $\begin{array}{l}\text { Sigma } \\
\text { Clone MY-32 } \\
\text { cat.no M4276 }\end{array}$ & $1: 300$ & Striated myotubes and fibers \\
\hline $\begin{array}{l}\text { Titin } \\
\text { (Ttn) }\end{array}$ & $\sim \mathrm{d} 25+$ & $\begin{array}{l}\text { DSHB } \\
\text { cat.no. 9 D10 }\end{array}$ & $1: 300$ & $\begin{array}{l}\text { Striated muscles } \\
\text { (Cardiomyocytes) }\end{array}$ \\
\hline $\begin{array}{l}\text { Dystrophin } \\
\text { (Dys) }\end{array}$ & $\sim \mathrm{d} 25+$ & $\begin{array}{l}\text { Zeiss/ } \\
\text { Novocastra } \\
\text { Clone Dy4/6D3 } \\
\text { cat.no. NCL- } \\
\text { DYS1 }\end{array}$ & $1: 200$ & Skeletal myofibers \\
\hline
\end{tabular}

Table 2: List of markers used to characterize the differentiating hPSC-derived myogenic cultures and corresponding antibodies for immunohistochemistry (Figures 2, 4, 5).

32| Wash cells 3 times with TBST for $5 \mathrm{~min}$.

33| Incubate cells in secondary antibodies conjugated with a fluorochrome and Hoechst diluted in Blocking solution overnight at $4^{\circ} \mathrm{C}$, on a shaker. CRITICAL STEP Protect cells from light from this step onwards.

34| Wash cells 3 times with TBST for $5 \mathrm{~min}$.

35| Add $250 \mu \mathrm{L} / \mathrm{cm}^{2}$ of DPBS to cells.

PAUSE POINT Store for up to 3 weeks for later analysis, light -protected at $4^{\circ} \mathrm{C}$.

36| Image cells with a fluorescence microscope equipped with the appropriate fluorescent filter cubes. 
CRITICAL STEP Despite being fairly stable, staining analysis should be performed within days to weeks to avoid signal fading and diffusion (Figures 2,4).

Culture expansion (Day 10+) • TIMING 3-4 d

CRITICAL Culture can be split anytime between Day 12 to Day $100+$ of culture. Cultures 30 Days + are a mix of myogenic progenitors (PAX7+, MYOD+ ), and postmitotic myocytes, myotubes and fully differentiated myofibers (MYOG+, MyHC+, Titin+) as well as other cell types including fibroblasts, neuronal contaminants (Figure 1c, day40). For best results, starting differentiated hPSC culture can be prescreened for its myogenic phenotype consisting in elongated bipolar cells organized in stream-like sheets of tissue (Figure 1c).

37| Passaging Differentiating cells and Myogenic progenitor culture expansion (Figure 3 ). Pre-treat cultures to be dissociated with $10 \mu \mathrm{M}$ Rock inhibitor in D-KHI medium for at least 2 hours.

38 | Prepare multiwell plates or dishes coated with Matrigel for subculture.

39 | Rinse cell culture to be dissociated with DPBS without Calcium and Magnesium.

40| Add $250 \mu \mathrm{l} / \mathrm{cm}^{2}$ of TrypLE Express and incubate at $37^{\circ} \mathrm{C}, 5 \% \mathrm{CO} 2$, for $5-7 \mathrm{~min}$.

41|Fragment mechanically the dissociating culture using two 25 gauge needle as scalpel, to promote further enzymatic dissociation.

42 Add an additional $250 \mu \mathrm{l} / \mathrm{cm}^{2}$ of TrypLE Express and incubate again at $37^{\circ} \mathrm{C}, 5 \%$ CO2, for 5-7 min.

43|Collect the dissociated cells and transfer into a $50 \mathrm{ml}$ tube containing $20 \mathrm{ml}$ of DMEM with $10 \%$ FBS.

44| Repeat step 40-43 until all the culture detached from the dish and composed of dissociated cells and larger aggregates. Complete enzymatic incubation should not exceed 45 min.

CRITICAL STEP Dissociation needs to be thorough enough to result in single cell suspension, but gentle enough not to reduce viability. Typically you should observe $>80 \%$ of viability immediately after dissociation.

CRITICAL STEP If 2 rounds of TrypLE Express incubation and mechanical fragmentation appears insufficient in dissociating the culture, TrypLE Express can be replaced by $0.25 \%$ Trypsin on the next round. Other enzyme mixes and concentrations have also been used successfully, including Dispase/Collagenase; Collagenase IV/ Trypsin-EDTA. Incubation time and trituration may have to be adjusted.

CAUTION Note that older cultures (50+ day old) cannot usually be fully dissociated and pieces of culture will remain undissociated. 
45 After dissociation of the cultures, further triturate the suspension with a $10 \mathrm{~mL}$ pipet to break cell clumps.

TROUBLESHOOTING

46| Filter cell suspension on a $70 \mu \mathrm{m}$ cell strainer placed on a $50 \mathrm{ml}$ collection tube.

47| Centrifuge cells at $300 \mathrm{~g}$ for $5 \mathrm{~min}$.

48| Remove supernatant and resuspend the pellet gently in Skeletal muscle Growth

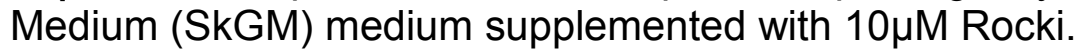

49| Count cells and use Trypan Blue or similar to assess cell viability

CRITICAL STEP Routinely, after dissociation with TrypLE/Trypsin, cell viability decrease with the age of the dissociated cultures. From $<30$ day-old culture, about $95 \%$ of cells are viable, while $85 \%$ from D30-D80 culture and $80 \%$ for D80-120 cultures.

50| Replate on Matrigel-coated wells at $60-70,000$ cells $/ \mathrm{cm}^{2}$ in SkGM $+10 \mu \mathrm{M}$ Rocki , corresponding approximatively to a subculturing ratio is 1:4-1:8 per surface area. (ie. $\sim 2.5 \times 10^{5}$ cells in $1.5 \mathrm{~mL}$ of medium for 1 well of a 12 well plate). 1 p35 dish can typically produce enough differentiated cells to cover half of a 12 -well plate.

CRITICAL STEP Cell density is critical and plating too few cells will prevent proliferation of progenitor cells. Replated cells should reach confluency within 3 days in SkGM media for optimal culture of progenitor cells.

51| Incubate the plate at $37^{\circ} \mathrm{C}$ with $5 \% \mathrm{CO}_{2}$ overnight.

52| Observe cell attachment and recovery, change SkGM medium every second day, until desired confluency is reached. Passage the culture which will now contain a high percentage of myogenic progenitors (Figure $3 d-j, 4$ ).

53| Expand the subculture (Figure 3). We recommend that stocks be cryopreserved at the earliest passages, ideally at every passage (Box 1) (Figure 4e).

CRITICAL STEP Cells can be further subcultured, over 100 days for downstream applications or kept in SkGM at high density without losing myogenic competency. TROUBLESHOOTING

54| To further differentiate the cells to myofibers, change media to Horse serum (HS) $2 \%$ medium after 3-4 days in SkGM. As a serum-free alternative, culture can be differentiated in N2 media (Figure 3c, e, g-j.

CAUTION While both HS and N2 -based media promote myofibers formation. N2 media, being less rich, may not be able to support differentiated cultures over extended time period ( $>2$ weeks) compared to HS-based medium.

\section{Box 1 Culture cryopreservation $\bullet$ TIMING $2 \mathrm{~d}$}

1. Dissociate primary culture or subcultures as in steps 37-44. 
2. Resuspend the pellet in $1 \mathrm{ml}$ DMEM/F12. CRITICAL STEP Cultures older than 30 -days will have persisting cell clumps after dissociation that can be frozen together with single cells and when replated will give rise to myogenic cells.

3. Centrifuge cells at $300 \mathrm{~g}$ for $5 \mathrm{~min}$, remove the supernatant and resuspend the pellet in Cryostem freezing medium. Optimal freezing density is approximated by eye due to existence of small clumps after dissociation. CRITICAL STEP As a guideline, one well of 6 -well plate for a $30+$ days culture can generate $5 \times 1 \mathrm{~mL}$ cryovials. Place cryovials in a freezing container at $-80^{\circ} \mathrm{C}$ overnight.

4. Next day, transfer cryovials to liquid nitrogen storage tank for long term storage. PAUSE POINT Frozen cryovials of cells can be kept indefinitely in liquid nitrogen END BOX

\section{Box 2 Cryostock thaw $\bullet$ TIMING $1 \mathrm{~d}$}

1. Transfer promptly frozen vials to a water bath set at $37^{\circ} \mathrm{C}$ until vials is partially thawed

2. Resuspend and transfer gently the vials content with $4 \mathrm{ml} \mathrm{DMEM} / \mathrm{F} 12$ in a $15 \mathrm{~mL}$ collection tube.

3. Centrifuge cells at $300 \mathrm{~g}$ for $5 \mathrm{~min}$, remove the supernatant and resuspend the pellet in SkGM. As a guideline for optimal seeding density, 1 vial as prepared in Box1 should be seeded one well of 24-well Matrigel coated plate. After 3 days, culture can be expanded again following steps 28-42

END BOX 



\section{- TIMING}

Steps 1-4, pluripotent cells preparation: $5-7 \mathrm{~d}$ Steps 5-19, predifferentiation setup: $2 \mathrm{~d}$ Steps 20-25, directed differentiation: $30-40 d+$ Steps $26-36$, characterization of myogenic cultures: $2-4 d$ Steps 37-54, culture expansion: 3-4d

Box1, culture cryopreservation: $2 \mathrm{~d}$

Box2, cryostock thaw: $1 \mathrm{~d}$

- TROUBLESHOOTING

See Table 2 for troubleshooting guidance. 
- Table 2 TROUBLESHOOTING TABLE

\begin{tabular}{|c|c|c|c|}
\hline Steps & Problem & Possible reason(s) & Solution(s) \\
\hline 19 & Poor cell survival & $\begin{array}{l}\text { Single cell dissociation } \\
\text { was done by pipetting } \\
\text { too forcefully or for too } \\
\text { long. }\end{array}$ & $\begin{array}{l}\text { Starting with healthy } \\
\text { undifferentiated hPSCs culture } \\
\text { with optimal colonies size, } \\
\text { before necrotic zone form at } \\
\text { their centers, at } \sim 70 \% \\
\text { confluence. Culture can be } \\
\text { more resistant to cell death by } \\
\text { treating them with the anti- } \\
\text { apoptotic Rocki and seed } \\
\text { dissociated cells in Rocki- } \\
\text { containing mTeSR. }\end{array}$ \\
\hline 19 & $\begin{array}{l}\text { Poor cell } \\
\text { attachment }\end{array}$ & $\begin{array}{l}\text { Matrigel was not coated } \\
\text { properly. } \\
\text { Starting hPSCs were } \\
\text { grown on feeders. }\end{array}$ & $\begin{array}{l}\text { Test Matrigel lot for routine } \\
\text { hPSCs culture maintenance. } \\
\text { Follow Matrigel coating } \\
\text { procedure properly ensuring it } \\
\text { is manipulated at } 4^{\circ} \mathrm{C} \text { at all } \\
\text { time. } \\
\text { Adapt hPSCs culture to } \\
\text { Matrigel +mTeSR maintenance } \\
\text { conditions. It may take several } \\
\text { passages, by manually } \\
\text { selecting undifferentiated } \\
\text { colonies. } \\
\text { Increase the seeding cell } \\
\text { number density. }\end{array}$ \\
\hline $20-23$ & $\begin{array}{l}\text { Cell cultures } \\
\text { detach en masse }\end{array}$ & $\begin{array}{l}\text { Cells were plated at too } \\
\text { high density. } \\
\text { The differentiation } \\
\text { protocol was started on } \\
\text { too dense culture. }\end{array}$ & $\begin{array}{l}\text { Optimize the seeding cell } \\
\text { density and the recovery time } \\
\text { before starting the } \\
\text { differentiation (variable cell line } \\
\text { to cell line). }\end{array}$ \\
\hline 25 & Poor myogenicity & $\begin{array}{l}\text { Signaling pathway } \\
\text { modulators are not } \\
\text { prepared correctly or } \\
\text { are not active. }\end{array}$ & $\begin{array}{l}\text { Start with healthy } \\
\text { undifferentiated hPSC culture. } \\
\text { Compare side-by side } \\
\text { differentiation of several cell } \\
\text { lines as differentiation efficiency } \\
\text { varies from cell line to cell line. } \\
\\
\text { Prepare chemical compounds } \\
\text { and recombinant proteins } \\
\text { according to the procedure and } \\
\text { reagent set-up to keep their } \\
\text { activity. }\end{array}$ \\
\hline
\end{tabular}




\begin{tabular}{|l|l|l|l|}
\hline Steps & Problem & Possible reason(s) & Solution(s) \\
\hline $\mathbf{4 5}$ & $\begin{array}{l}\text { Poor cell dissociation } \\
\text { Cell culture is } \\
\text { resistant to } \\
\text { enzymatic } \\
\text { dissociation }\end{array}$ & $\begin{array}{l}\text { Culture is very dense } \\
\text { and deposits of } \\
\text { extracellular matrix } \\
\text { block the activity of the } \\
\text { enzyme. }\end{array}$ & $\begin{array}{l}\text { Preincubate in DPBS for } \\
1 \text { Omin, to } \\
\text { loosen up cell adhesion. } \\
\text { Triturate the culture } \\
\text { mechanically with needles } \\
\text { before and during enzymatic } \\
\text { dissociation. }\end{array}$ \\
\hline $\mathbf{5 3}$ & $\begin{array}{l}\text { Poor myogenicity in } \\
\text { subcultures }\end{array}$ & $\begin{array}{l}\text { Proliferative } \\
\text { contaminant cell } \\
\text { populations invade the } \\
\text { culture. }\end{array}$ & $\begin{array}{l}\text { intensity of enzymath and } \\
\text { incubation while pretreating } \\
\text { the culture with Rocki }\end{array}$ \\
\hline $\begin{array}{l}\text { Dissociate more mature } \\
\text { cultures that are less likely } \\
\text { to contain proliferative } \\
\text { contaminants. }\end{array}$ \\
\hline
\end{tabular}




\section{- ANTICIPATED RESULTS}

This protocol allows for the efficient production of expandable muscle progenitors from hPSCs that can be amplified, subcultured, cryopreserved, further differentiated into skeletal myofibers and characterized. The derivation of the muscle progenitors is achieved by a sequence of differentiation media with defined compositions that directs hPSCs to form paraxial mesoderm and further differentiate into myoblasts.

\section{Primary differentiation}

The differentiation reagent setup and the first week of differentiation are the most critical steps for successful myogenic differentiation. Following cell seeding, cells recover by reforming evenly distributed adherent small and irregular cell aggregates within 1-2 days in mTeSR + Rocki up to $15-20 \%$ confluence (Figure 1c). During the first week, the culture goes through several crisis phases associated with significant cell death, possibly due to the selective action of the sequence of differentiation media (Figure 1c). We usually observe that the addition of bFGF at day 3 leads to important cellular aggregates rearrangements in the culture. Surviving mesodermal progenitors with a mesenchymal phenotype proliferate and become confluent within a week (Figure1c). Differentiation into paraxial mesoderm can be monitored by the expression of Tbx6 around day 4-5 of differentiation, and Tbx6-positive population should account for about $80 \%$ of the total culture at day4 (Figure 2). Proper progression to an anterior PSM fate and dermomyotomal specification can be assessed by the activation of Pax3 expression starting around 1 week of differentiation until 3 weeks (Figure 2). Further myogenic commitment can be assessed by expression of the muscle regulatory factors in particular MyoD and Myogenin, as well as Pax7-positive progenitors. By 4 weeks of differentiation, both Myog+ and Pax7+ populations represent combined $40-50 \%$ of the total nuclei. Myotubes/myofibers will be also clearly visible by phase-contrast as early as 4 weeks (30 days + ) and mature over additional 5 weeks+ of culture (Figure 3e, g-i). At this stage, fibers can be millimeter-long, exhibit striations, best evidenced by immunohistochemistry for sarcomeric proteins, such as Titin and Myosin heavy chain (Figure 2b). Maturity of the contractile apparatus is evidenced by spontaneous twitching. While the myogenic culture become very dense and tends to detach after 4 weeks of 
culture, it still contains myogenic progenitors (Figure 1c). It is then advisable to proceed for analysis or to passage the culture for expansion (Figure 3). The expected Fast MyHC -positive fibers yield with this protocol is around $0.6-0.9$ cell per hPSC cell seeded initially ${ }^{1}$.

\section{Subculture and secondary differentiation}

The dissociation of the dense primary culture will eliminate dead cells, debris, ECM deposit, unwanted derivatives but also existing (postmitotic) myofibers (Figure 3d). About $80 \%$ of the single mononucleated cells isolated are viable. The replating in Skeletal Muscle Growth Media selectively promotes myogenic progenitors expansion. This leads to more homogeneous, less dense cultures of proliferating myogenic progenitors and eliminates lots of cell debris and unwanted derivatives that are byproduct of the differentiation (compare Figure 1c and 3d). With seeding at 60-70,000 cells $/ \mathrm{cm}^{2}$ corresponding approximately to a subculture ratio of $1: 4$ to $1: 8$, culture confluence is achieved again within few days forming a sheet of elongated bipolar myoblasts. We found that confluent subcultures can be maintained in SkGM media for an extended period of time without losing their myogenic potential when further passaged. Switch to K-HI, N2 media or alternatively Horse serum- based media will promote further myogenic differentiation and fusion of progenitors (Figure 3c). This can be achieved within a week, although muscle fibers continue to mature for 2 weeks, as evidenced by fiber size and myofibrills. Mature fibers from subcultures measure up to several millimeters in length with a width ranging from 5 to $20+\mu m$ (Figure $2 b, 4,5$ ). As for the primary culture, myogenic differentiation can be monitored and cellular phenotype can be assessed by immunohistochemistry (Figure 4). After replating, up to $40 \%$ of total nuclei (from 3 independent cell lines) were Myog-positive and mature skeletal myofiber density was ranging from 9,000 to 20,000 fibers per $\mathrm{cm}^{2}$ (Figure $5 \mathrm{c}-\mathrm{d}$ ). 


\section{Acknowledgements}

We thank all co-authors of the original article describing this technology for their initial support and contribution. We thank Getzabel Guevara for lab assistance. We thank Charlotte Fugier and Fanny Bousson for comments and feedbacks. We are grateful to Laurence Daheron and members of the Pourquié laboratory for comments. We thank Amélie Freismuth and Marion Humbert from the IGBMC cell culture service for hiPSC culture assistance. This work was supported by an advanced grant from the European Research Council to O.P., by the FP7 EU grant Plurimes (agreement no. 602423), by a strategic grant from the French Muscular Dystrophy Association (AFM) to O.P., and by the INGESTEM project (ANR).

\section{Author contributions}

J.C. and Z.A.T designed and performed experiments and protocol optimizations, analyzed data and coordinated the project. M.H and S.A carried out hPSCs differentiation and protocol optimization under the supervision of J.C. B.G. carried out some hPSCs optimization experiments under the supervision of Z.A.T. A.H. contributed to hiPS cell culture analysis and data interpretation. T.C. contributed to hiPSC culture differentiation and analysis. A.P.N. manufactured micropatterned substrates and performed the fiber structural analysis. K.K.P. provided expertise. O.P. supervised the overall project. J.C., Z.A.T and O.P. performed the final data analysis and wrote the manuscript.

\section{Competing financial interests}

The authors declare competing financial interests: details are available in the online version of the paper. The work described in this article is partially covered by patent application no. PCT/EP2012/066793 (publication no. WO2013030243 A1). O.P. and J.C. are co-founders and shareholders of Anagenesis Biotechnologies, a startup company specializing in production of muscle cells in vitro for cell therapy and drug screening. 


\section{FIGURES}

Figure 1 |Maintenance and Step-wise protocol for myogenic differentiation in vitro and phase-contrast images of differentiating cultures (Steps 1-25)

(a) Maintenance of undifferentiated hPSC culture. Representative NCRM1 hPSC colonies cultured on Matrigel-coated plate in mTeSR medium. Small colonies (left) growth within few days to colonies (middle left) ready for passaging or for differentiation set-up. Note the well defined, refringent colonies' borders. Note the tightly packed and smooth appearance of the colonies' centers. (middle right) Representative grid pattern for hPSC colonies using the cutting method ${ }^{61,62}$ for undifferentiated hPSC colonies passaging. The resulting colony pieces have been collected. (right) hPSC colony pieces immediately after transfer to a new Matrigel-coated dish. Scale bar, $1 \mathrm{~mm}$. Corresponding procedure steps are shown below.

(b) Diagram of the myogenic differentiation protocol of human pluripotent stem cells (hPSCs) highlighting key culturing steps (arrows) and their associated time scale. hPSCs were seeded as single cells on Matrigel-coated dishes (left) and differentiated over several weeks. Mature muscle fibers and their associated progenitors can be obtained directly from the primary culture. The sequence of media aims at modulating specific signaling pathways, notably $\mathrm{Wnt}$ and BMP signaling pathways. C: CHIRON99021, L: LDN193189, F: FGF-2, K: KSR, H: HGF, I: IGF-1.

Corresponding procedure steps are shown below.

(c) Representative phase-contrast images of the differentiating hiPS11a cultures following the protocol depicted in (a). Time course is shown in days (dx). Top panels, scale bar is $1 \mathrm{~mm}$, bottom panels, scale bar is $400 \mu \mathrm{m}$ (except $\mathrm{d} 5,1 \mathrm{~mm}$ ).

Figure 2| Immunophenotyping of hPSC-derived myogenic cultures (Steps 26-36)

(a) Diagram mapping the developmental stages of paraxial mesoderm differentiation and skeletal myogenesis from human pluripotent stem cells (hPSC) highlighting key markers and a timeline of their approximate expression.

(b) Primary differentiation. Representative expression sequence of markers detected by immmuno-histochemistry (Table 1) in hiPS11a culture differentiated according to Figure 2b. Paraxial mesoderm (Tbx6-positive) population peaks around Day 4 of differentiation. Dermomyotomal progenitors (Pax3-positive) are detectable as early as 1 week of 
differentiation and increase during week 2. Starting at 2 weeks, large fields of Myogenin (Myog)-positive myocytes appear. By 4 weeks, cultures comprise large sheets of MyHC-positive myofibers (Fast MyHC and MF20 -positive) and Pax7-positive satellitelike cells. Scale bar, $400 \mu \mathrm{m}$. By day40-50, the primary differentiation generate large

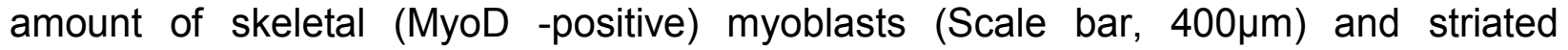

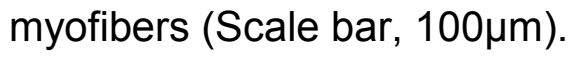

\section{Figure 3 |Subculturing of hPSC-derived myogenic culture (Steps 37-54)}

(a-c) Diagram of the subculturing protocol, expansion and secondary myogenic differentiation. (a) After 3 weeks of differentiation, the culture can be enzymatically dissociated for passaging. (b) Subcultures can be amplified in Skeletal Muscle Growth Media (SkGM) similar to a myogenic cell line, to generate frozen stocks and for downstream applications. (c) As needed, the culture can be further subcultured at high density and differentiated to myofibers. K: KSR, H: HGF, I: IGF-1, SkGM: Skeletal Muscle Growth Media, N2: N2-based medium, HS: Horse serum -based medium.

(d-j) Representative phase-contrast images of hPSC -myogenic progenitors subculture following the protocol depicted in (a-c). Inset label sdxdy: passaged at day $x$ and day $y$ of differentiation. Except when otherwise noted, redifferentiated subcultures were first maintained for 4 days in SkGM medium before changing to differentiation medium (d) 40 day-old hiPS11a cultures passaged once or twice as indicated and expanded in SkGM medium. Compare with primary differentiation at day40 (Figure 2b). (top panels)

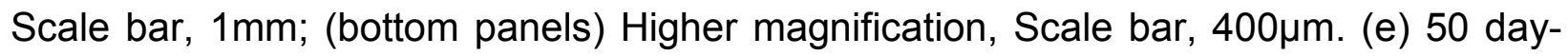
old hiPS11a cultures passaged once and maintained in SkGM medium for 17 days (left) or further differentiated in N2 medium after 4 days in SkGM medium (right). Scale bar, $1 \mathrm{~mm}$. Note the elongated refringent myofibers in N2 medium (>N2). (f) NCRM1 -derived myogenic subculture subcultured once at d68, maintained in SkGM and imaged at d84. Scale bar, $400 \mu \mathrm{m}$.

(g) Long term H9 myogenic culture passaged and redifferentiated in N2 medium (>N2) with fully differentiated millimeter-scale skeletal muscle fibers. Scale bar, $1 \mathrm{~mm}$. (h) Long term NCRM1 myogenic culture passaged twice, maintained in SkGM medium for 4 days and redifferentiated in Horse serum 2\% (>HS) with differentiated millimeter- 
scale skeletal muscle fibers. Scale bar, $1 \mathrm{~mm}$. (i) Detail of skeletal myofibers in NCRM1 subculture after 10 days of secondary differentiation in N2 medium (>N2) according to (a-c). Scale bar, $100 \mu \mathrm{m}$. (j) Spontaneous bundles formation in 38 day -old hiPS11a myogenic cultures maintained at high density in SkGM. Scale bar, $1 \mathrm{~mm}$.

\section{Figure 4 | Immunophenotyping of myogenic subcultures (Steps 26-36)}

Subcultures can be maintained in SkGM medium or redifferentiated to obtain myofibers. Except when otherwise noted, redifferentiated subcultures were first maintained for 4 days in SkGM medium before changing to differentiation medium. Inset label sdxdy: passaged at day $x$ and day $y$ of differentiation.

(a) hiPS11a culture passaged once and re-differentiated in D-KHI (>K-HI) medium. (left) Large MyHC (MF20) -positive skeletal fibers and associated Pax7-positive progenitors are detected within 10 days. (right) $10 \mu \mathrm{m}+$ wide fibers are Fast MyHC-positive. Scale bar, $400 \mu \mathrm{m}$.

(b) 40 day-old NCRM1 cultures passaged once and re-differentiated in N2 (>N2) medium. (left)

Differentiated subcultures retained a Pax7-positive population interspersed with differentiated Myog-positive cells. (right) Most of the Myog-positive myonuclei are incorporated in large millimeter-size Fast MyHC -positive skeletal fibers. Scale bar, $400 \mu \mathrm{m}$.

(c) Long term NCRM1 culture passaged once, expanded in SkGM medium and redifferentiated (right) or not (left) in N2 medium. Passaging allows for a homogeneous amplification of progenitors that in turn give rise to myocytes (Myogenin- positive) that can be differentiated to mature striated skeletal muscle fibers (Titin-positive). Scale bar, $400 \mu \mathrm{m}$.

(d) Long term NCRM1 culture passaged once, maintained in SkGM for 4 days and redifferentiated into DK-HI medium. (top) Note large fieds of skeletal fibers evidenced by Titin and Myog expression. (bottom) detail of the myofibers. Scale bar, $1 \mathrm{~mm}$ (top), $200 \mu \mathrm{m}$ (bottom). 
(e) Sarcomeric organization and multinucleation of NCRM1- derived myofibers redifferentiated in N2 medium. Nuclei are counterstained with Hoechst (blue). Arrowheads note aligned myonuclei. Scale bar, $100 \mu \mathrm{m}$.

(f) Example of hiPS11a-derived Dystrophin (Dys)-positive myofibers (green) obtained after multiple passaging. Nuclei were counterstained with Hoechst (blue). Scale bar, $100 \mu \mathrm{m}$.

(g) Cryopreservation and recovery. Dissociated hiPS11a culture was cryopreserved at day58, thawed, expanded in SkGM and redifferentiated in Horse serum-based medium (>HS). Nuclei were counterstained with Hoechst (blue). Note the large fields of Titinpositive myofibers. Scale bar, $400 \mu \mathrm{m}$.

\section{Figure 5 | Example of downstream applications for hPSC-derived myogenic cultures}

(a) Muscle construct. hiPS11a -derived myogenic subculture was used to make muscle constructs according to ${ }^{70}$. (top left) The centimeter-long fascicle-like muscle construct spontaneously assemble around silk suture anchors (phase-contrast, inset is a lower magnification showing the silk anchor ( ${ }^{*}$, scale bar, $1 \mathrm{~mm}$ ). Scale bar, $400 \mu \mathrm{m}$. (top right) The construct contains hundreds of aligned human skeletal fibers visualized in cross section with Titin staining (green) and nuclear counterstaining (blue). Scale bar, $1 \mathrm{~mm}$. (bottom) Details of top right panel, Scale bar, $400 \mu \mathrm{m}$.

(b) Distribution of Fast MyHC and Dystrophin in transversal sections of hiPS11a derived muscle constructs as described in Figure 5a. Arrowheads show individual fibers delimited by Laminin (Lam). Scale bar, $25 \mu \mathrm{m}$.

(c) Micropatterned skeletal muscle fiber array (Muscle chip). NCRM1-derived myogenic subculture was seeded on micropatterned substrate composed of adhesion permissive stripes, prepared according to ${ }^{187}$. (Top left) Overview of the array showing differentiated Titin-positive skeletal myofibers. Note overall alignment from left to right. Scale bar, $1 \mathrm{~mm}$. (Top right) Representative distribution diagram of myofibers' alignment on an $1800 \times 1500 \mu \mathrm{m}$ array area (dotted white box in Top left panel) relative to the orientation of the substrate. Structural analysis was done according to ${ }^{188}$. The orientational order 
parameter (OOP) is close to 1. (Bottom) Detail of top left panel, striated skeletal fibers

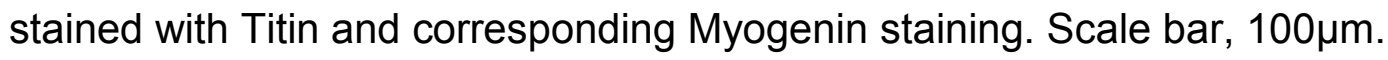

(d) Proportion of Myogenin -positive nuclei after 2 weeks of culture on muscle chips described in Figure 5c. Quantifications for three hPSC lines are shown. For each cell line, duplicate chips (arrays) were generated and 3 fields of view ( $>4,000$ nuclei per chip) were quantified by device. Errors bars, means $+/-$ sd. 


\section{References}

1 Chal, J. et al. Differentiation of pluripotent stem cells to muscle fiber to model Duchenne muscular dystrophy. Nature biotechnology 33, 962-969, doi:10.1038/nbt.3297 (2015).

2 Rohwedel, J. et al. Muscle cell differentiation of embryonic stem cells reflects myogenesis in vivo: developmentally regulated expression of myogenic determination genes and functional expression of ionic currents. Developmental biology 164, 87-101, doi:10.1006/dbio.1994.1182 (1994).

3 Wobus, A. M. Potential of embryonic stem cells. Molecular aspects of medicine 22, 149-164 (2001).

4 Greco, T. L. et al. Analysis of the vestigial tail mutation demonstrates that Wnt-3a gene dosage regulates mouse axial development. Genes \& development 10, 313-324 (1996).

5 Aulehla, A. et al. A beta-catenin gradient links the clock and wavefront systems in mouse embryo segmentation. Nature cell biology 10, 186-193, doi:10.1038/ncb1679 (2008).

6 Dunty, W. C., Jr. et al. Wnt3a/beta-catenin signaling controls posterior body development by coordinating mesoderm formation and segmentation. Development 135, 85-94, doi:10.1242/dev.009266 (2008).

7 Yamaguchi, T. P., Takada, S., Yoshikawa, Y., Wu, N. \& McMahon, A. P. T (Brachyury) is a direct target of Wnt3a during paraxial mesoderm specification. Genes \& development 13, 3185-3190 (1999).

8 Chal, J. \& Pourquie, O. Patterning and Differentiation of the Vertebrate Spine. Cold Spring Harbor Monograph The Skeletal System, 41-116 (2009).

9 Yoshikawa, Y., Fujimori, T., McMahon, A. P. \& Takada, S. Evidence that absence of Wnt-3a signaling promotes neuralization instead of paraxial mesoderm development in the mouse. Developmental biology 183, 234-242, doi:10.1006/dbio.1997.8502 (1997).

10 Chapman, D. L., Agulnik, I., Hancock, S., Silver, L. M. \& Papaioannou, V. E. Tbx6, a mouse T-Box gene implicated in paraxial mesoderm formation at gastrulation. Developmental biology 180, 534-542, doi:10.1006/dbio.1996.0326 (1996).

11 Galceran, J., Farinas, I., Depew, M. J., Clevers, H. \& Grosschedl, R. Wnt3a-/-like phenotype and limb deficiency in Lef1(-/-)Tcf1(-/-) mice. Genes \& development 13, 709-717 (1999).

12 Lindsley, R. C., Gill, J. G., Kyba, M., Murphy, T. L. \& Murphy, K. M. Canonical Wnt signaling is required for development of embryonic stem cell-derived mesoderm. Development 133, 3787-3796, doi:10.1242/dev.02551 (2006).

13 Gadue, P., Huber, T. L., Paddison, P. J. \& Keller, G. M. Wnt and TGF-beta signaling are required for the induction of an in vitro model of primitive streak formation using embryonic stem cells. Proceedings of the National Academy of Sciences of the United States of America 103, 16806-16811, doi:10.1073/pnas.0603916103 (2006).

14 Sumi, T., Tsuneyoshi, N., Nakatsuji, N. \& Suemori, H. Defining early lineage specification of human embryonic stem cells by the orchestrated balance of 
canonical Wnt/beta-catenin, Activin/Nodal and BMP signaling. Development 135, 2969-2979, doi:10.1242/dev.021121 (2008).

15 Nakanishi, M. et al. Directed induction of anterior and posterior primitive streak by Wnt from embryonic stem cells cultured in a chemically defined serum-free medium. FASEB journal : official publication of the Federation of American Societies for Experimental Biology 23, 114-122, doi:10.1096/fj.08-111203 (2009).

$16 \mathrm{Xu}, \mathrm{C}$. et al. A zebrafish embryo culture system defines factors that promote vertebrate myogenesis across species. Cell 155, 909-921, doi:10.1016/j.cell.2013.10.023 (2013).

17 Borchin, B., Chen, J. \& Barberi, T. Derivation and FACS-mediated purification of PAX3+/PAX7+ skeletal muscle precursors from human pluripotent stem cells. Stem cell reports 1, 620-631, doi:10.1016/j.stemcr.2013.10.007 (2013).

18 Shelton, M. et al. Derivation and expansion of PAX7-positive muscle progenitors from human and mouse embryonic stem cells. Stem cell reports 3, 516-529, doi:10.1016/j.stemcr.2014.07.001 (2014).

19 Hwang, Y. et al. WNT3A promotes myogenesis of human embryonic stem cells and enhances in vivo engraftment. Scientific reports 4, 5916, doi:10.1038/srep05916 (2014).

20 Aulehla, A. et al. Wnt3a plays a major role in the segmentation clock controlling somitogenesis. Developmental cell 4, 395-406 (2003).

21 Geetha-Loganathan, P., Nimmagadda, S., Scaal, M., Huang, R. \& Christ, B. Wnt signaling in somite development. Annals of anatomy = Anatomischer Anzeiger : official organ of the Anatomische Gesellschaft 190, 208-222, doi:10.1016/j.aanat.2007.12.003 (2008).

22 Tonegawa, A., Funayama, N., Ueno, N. \& Takahashi, Y. Mesodermal subdivision along the mediolateral axis in chicken controlled by different concentrations of BMP-4. Development 124, 1975-1984 (1997).

23 Hirsinger, E. et al. Noggin acts downstream of Wnt and Sonic Hedgehog to antagonize BMP4 in avian somite patterning. Development 124, 4605-4614 (1997).

24 McMahon, J. A. et al. Noggin-mediated antagonism of BMP signaling is required for growth and patterning of the neural tube and somite. Genes \& development 12, 1438-1452 (1998).

25 Reshef, R., Maroto, M. \& Lassar, A. B. Regulation of dorsal somitic cell fates: BMPs and Noggin control the timing and pattern of myogenic regulator expression. Genes \& development 12, 290-303 (1998).

26 Streit, A. \& Stern, C. D. Mesoderm patterning and somite formation during node regression: differential effects of chordin and noggin. Mechanisms of development 85, 85-96 (1999).

27 Miura, S., Davis, S., Klingensmith, J. \& Mishina, Y. BMP signaling in the epiblast is required for proper recruitment of the prospective paraxial mesoderm and development of the somites. Development 133, 3767-3775, doi:10.1242/dev.02552 (2006).

28 Sela-Donenfeld, D. \& Kalcheim, C. Localized BMP4-noggin interactions generate the dynamic patterning of noggin expression in somites. Developmental biology 246, 311-328, doi:10.1006/dbio.2002.0672 (2002). 
29 Morizane, R. et al. Nephron organoids derived from human pluripotent stem cells model kidney development and injury. Nature biotechnology 33, 1193-1200, doi:10.1038/nbt.3392 (2015).

30 Umeda, K. et al. Human chondrogenic paraxial mesoderm, directed specification and prospective isolation from pluripotent stem cells. Scientific reports 2, 455, doi:10.1038/srep00455 (2012).

31 Adelman, C. A., Chattopadhyay, S. \& Bieker, J. J. The BMP/BMPR/Smad pathway directs expression of the erythroid-specific EKLF and GATA1 transcription factors during embryoid body differentiation in serum-free media. Development 129, 539-549 (2002).

32 Nostro, M. C., Cheng, X., Keller, G. M. \& Gadue, P. Wnt, activin, and BMP signaling regulate distinct stages in the developmental pathway from embryonic stem cells to blood. Cell stem cell 2, 60-71, doi:10.1016/j.stem.2007.10.011 (2008).

33 Lengerke, C. et al. BMP and Wnt specify hematopoietic fate by activation of the Cdx-Hox pathway. Cell stem cell 2, 72-82, doi:10.1016/j.stem.2007.10.022 (2008).

34 Orlova, V. V., Chuva de Sousa Lopes, S. \& Valdimarsdottir, G. BMP-SMAD signaling: From pluripotent stem cells to cardiovascular commitment. Cytokine \& growth factor reviews, doi:10.1016/j.cytogfr.2015.11.007 (2015).

35 Vivarelli, E. \& Cossu, G. Neural control of early myogenic differentiation in cultures of mouse somites. Developmental biology 117, 319-325 (1986).

36 Cossu, G., Kelly, R., Di Donna, S., Vivarelli, E. \& Buckingham, M. Myoblast differentiation during mammalian somitogenesis is dependent upon a community effect. Proceedings of the National Academy of Sciences of the United States of America 92, 2254-2258 (1995).

37 Buffinger, N. \& Stockdale, F. E. Myogenic specification of somites is mediated by diffusible factors. Developmental biology 169, 96-108, doi:10.1006/dbio.1995.1130 (1995).

38 Rong, P. M., Teillet, M. A., Ziller, C. \& Le Douarin, N. M. The neural tube/notochord complex is necessary for vertebral but not limb and body wall striated muscle differentiation. Development 115, 657-672 (1992).

39 Miller, J. B., Everitt, E. A., Smith, T. H., Block, N. E. \& Dominov, J. A. Cellular and molecular diversity in skeletal muscle development: news from in vitro and in vivo. BioEssays : news and reviews in molecular, cellular and developmental biology 15, 191-196, doi:10.1002/bies.950150308 (1993).

40 Neville, C., Rosenthal, N., McGrew, M., Bogdanova, N. \& Hauschka, S. Skeletal muscle cultures. Methods in cell biology 52, 85-116 (1997).

41 Danoviz, M. E. \& Yablonka-Reuveni, Z. Skeletal muscle satellite cells: background and methods for isolation and analysis in a primary culture system. Methods in molecular biology 798, 21-52, doi:10.1007/978-1-61779-343-1_2 (2012).

42 Miller, J. B. \& Stockdale, F. E. Developmental origins of skeletal muscle fibers: clonal analysis of myogenic cell lineages based on expression of fast and slow myosin heavy chains. Proceedings of the National Academy of Sciences of the United States of America 83, 3860-3864 (1986). 
43 Rutz, R. \& Hauschka, S. Clonal analysis of vertebrate myogenesis. VII. Heritability of muscle colony type through sequential subclonal passages in vitro. Developmental biology 91, 103-110 (1982).

44 Lian, $X$. et al. Efficient differentiation of human pluripotent stem cells to endothelial progenitors via small-molecule activation of WNT signaling. Stem cell reports 3, 804-816, doi:10.1016/j.stemcr.2014.09.005 (2014).

45 Tesar, P. J. et al. New cell lines from mouse epiblast share defining features with human embryonic stem cells. Nature 448, 196-199, doi:10.1038/nature05972 (2007).

46 Shelton, M., Kocharyan, A., Liu, J., Skerjanc, I. S. \& Stanford, W. L. Robust generation and expansion of skeletal muscle progenitors and myocytes from human pluripotent stem cells. Methods, doi:10.1016/j.ymeth.2015.09.019 (2015).

47 Mahmood, A., Harkness, L., Schroder, H. D., Abdallah, B. M. \& Kassem, M. Enhanced differentiation of human embryonic stem cells to mesenchymal progenitors by inhibition of TGF-beta/activin/nodal signaling using SB-431542. Journal of bone and mineral research : the official journal of the American Society for Bone and Mineral Research 25, 1216-1233, doi:10.1002/jbmr.34 (2010).

48 Hosoyama, T., McGivern, J. V., Van Dyke, J. M., Ebert, A. D. \& Suzuki, M. Derivation of myogenic progenitors directly from human pluripotent stem cells using a sphere-based culture. Stem cells translational medicine 3, 564-574, doi:10.5966/sctm.2013-0143 (2014).

49 Maffioletti, S. M. et al. Efficient derivation and inducible differentiation of expandable skeletal myogenic cells from human ES and patient-specific iPS cells. Nature protocols 10, 941-958, doi:10.1038/nprot.2015.057 (2015).

50 Shoji, E., Woltjen, K. \& Sakurai, H. Directed Myogenic Differentiation of Human Induced Pluripotent Stem Cells. Methods in molecular biology 1353, 89-99, doi:10.1007/7651_2015_257 (2016).

51 Albini, S. \& Puri, P. L. Generation of myospheres from hESCs by epigenetic reprogramming. Journal of visualized experiments : JoVE, e51243, doi:10.3791/51243 (2014).

52 Gerli, M. F., Maffioletti, S. M., Millet, Q. \& Tedesco, F. S. Transplantation of induced pluripotent stem cell-derived mesoangioblast-like myogenic progenitors in mouse models of muscle regeneration. Journal of visualized experiments : JoVE, e50532, doi:10.3791/50532 (2014).

53 Darabi, R. \& Perlingeiro, R. C. Derivation of Skeletal Myogenic Precursors from Human Pluripotent Stem Cells Using Conditional Expression of PAX7. Methods in molecular biology 1357, 423-439, doi:10.1007/7651_2014_134 (2016).

54 Stavropoulos, M. E., Mengarelli, I. \& Barberi, T. Differentiation of multipotent mesenchymal precursors and skeletal myoblasts from human embryonic stem cells. Current protocols in stem cell biology Chapter 1, Unit 1F 8, doi:10.1002/9780470151808.sc01f08s9 (2009).

55 Filareto, A. et al. An ex vivo gene therapy approach to treat muscular dystrophy using inducible pluripotent stem cells. Nature communications 4, 1549, doi:10.1038/ncomms2550 (2013). 
56 Quattrocelli, M. et al. Intrinsic cell memory reinforces myogenic commitment of pericyte-derived iPSCs. The Journal of pathology 223, 593-603, doi:10.1002/path.2845 (2011).

57 Barberi, T. et al. Derivation of engraftable skeletal myoblasts from human embryonic stem cells. Nature medicine 13, 642-648, doi:10.1038/nm1533 (2007).

58 Beers, J. et al. Passaging and colony expansion of human pluripotent stem cells by enzyme-free dissociation in chemically defined culture conditions. Nature protocols 7, 2029-2040, doi:10.1038/nprot.2012.130 (2012).

59 Baharvand, H., Salekdeh, G. H., Taei, A. \& Mollamohammadi, S. An efficient and easy-to-use cryopreservation protocol for human ES and iPS cells. Nature protocols 5, 588-594, doi:10.1038/nprot.2009.247 (2010).

60 Marti, M. et al. Characterization of pluripotent stem cells. Nature protocols 8, 223253, doi:10.1038/nprot.2012.154 (2013).

61 Schwartz, P. H., Brick, D. J., Nethercott, H. E. \& Stover, A. E. Traditional human embryonic stem cell culture. Methods in molecular biology 767, 107-123, doi:10.1007/978-1-61779-201-4_8 (2011).

62 Lin, S. \& Talbot, P. Methods for culturing mouse and human embryonic stem cells. Methods in molecular biology 690, 31-56, doi:10.1007/978-1-60761-9628_2 (2011).

63 van den Brink, S. C. et al. Symmetry breaking, germ layer specification and axial organisation in aggregates of mouse embryonic stem cells. Development 141, 4231-4242, doi:10.1242/dev.113001 (2014).

64 Gouti, M. et al. In vitro generation of neuromesodermal progenitors reveals distinct roles for wht signalling in the specification of spinal cord and paraxial mesoderm identity. PLoS biology 12, e1001937, doi:10.1371/journal.pbio.1001937 (2014).

65 Rohwedel, J., Guan, K., Hegert, C. \& Wobus, A. M. Embryonic stem cells as an in vitro model for mutagenicity, cytotoxicity and embryotoxicity studies: present state and future prospects. Toxicology in vitro : an international journal published in association with BIBRA 15, 741-753 (2001).

66 Giobbe, G. G. et al. Functional differentiation of human pluripotent stem cells on a chip. Nature methods 12, 637-640, doi:10.1038/nmeth.3411 (2015).

67 Park, D., Lim, J., Park, J. Y. \& Lee, S. H. Concise Review: Stem Cell Microenvironment on a Chip: Current Technologies for Tissue Engineering and Stem Cell Biology. Stem cells translational medicine 4, 1352-1368, doi:10.5966/sctm.2015-0095 (2015).

68 Ostrovidov, S. et al. Skeletal muscle tissue engineering: methods to form skeletal myotubes and their applications. Tissue engineering. Part B, Reviews 20, 403436, doi:10.1089/ten.TEB.2013.0534 (2014).

69 Cheng, C. W., Solorio, L. D. \& Alsberg, E. Decellularized tissue and cell-derived extracellular matrices as scaffolds for orthopaedic tissue engineering. Biotechnology advances 32, 462-484, doi:10.1016/j.biotechadv.2013.12.012 (2014).

70 Dennis, R. G. \& Kosnik, P. E., 2nd. Excitability and isometric contractile properties of mammalian skeletal muscle constructs engineered in vitro. In vitro 
cellular \& developmental biology. Animal 36, 327-335, doi:10.1290/10712690(2000)036<0327:EAICPO>2.0.CO;2 (2000).

71 Bian, W. \& Bursac, N. Engineered skeletal muscle tissue networks with controllable architecture. Biomaterials 30, 1401-1412, doi:10.1016/j.biomaterials.2008.11.015 (2009).

72 Juhas, M. \& Bursac, N. Engineering skeletal muscle repair. Current opinion in biotechnology 24, 880-886, doi:10.1016/j.copbio.2013.04.013 (2013).

73 Sakar, M. S. et al. Formation and optogenetic control of engineered 3D skeletal muscle bioactuators. Lab on a chip 12, 4976-4985, doi:10.1039/c2lc40338b (2012).

74 Neal, D., Sakar, M. S., Ong, L. L. \& Harry Asada, H. Formation of elongated fascicle-inspired 3D tissues consisting of high-density, aligned cells using sacrificial outer molding. Lab on a chip 14, 1907-1916, doi:10.1039/c4lc00023d (2014).

75 Grosberg, A. et al. Muscle on a chip: in vitro contractility assays for smooth and striated muscle. Journal of pharmacological and toxicological methods 65, 126135, doi:10.1016/j.vascn.2012.04.001 (2012).

76 Benam, K. H. et al. Engineered in vitro disease models. Annual review of pathology 10, 195-262, doi:10.1146/annurev-pathol-012414-040418 (2015).

77 Vandenburgh, H. Functional assessment and tissue design of skeletal muscle. Annals of the New York Academy of Sciences 961, 201-202 (2002).

78 Vandenburgh, H., Shansky, J., Del Tatto, M. \& Chromiak, J. Organogenesis of skeletal muscle in tissue culture. Methods in molecular medicine 18, 217-225, doi:10.1385/0-89603-516-6:217 (1999).

79 Vandenburgh, $\mathrm{H}$. et al. Automated drug screening with contractile muscle tissue engineered from dystrophic myoblasts. FASEB journal : official publication of the Federation of American Societies for Experimental Biology 23, 3325-3334, doi:10.1096/fj.09-134411 (2009).

80 Vandenburgh, $\mathrm{H}$. et al. Drug-screening platform based on the contractility of tissue-engineered muscle. Muscle \& nerve 37, 438-447, doi:10.1002/mus.20931 (2008).

81 Demestre, M. et al. Formation and characterisation of neuromuscular junctions between hiPSC derived motoneurons and myotubes. Stem cell research 15, 328336, doi:10.1016/j.scr.2015.07.005 (2015).

82 Das, M., Rumsey, J. W., Bhargava, N., Stancescu, M. \& Hickman, J. J. Skeletal muscle tissue engineering: a maturation model promoting long-term survival of myotubes, structural development of the excitation-contraction coupling apparatus and neonatal myosin heavy chain expression. Biomaterials 30, 53925402, doi:10.1016/j.biomaterials.2009.05.081 (2009).

83 Das, M., Rumsey, J. W., Bhargava, N., Stancescu, M. \& Hickman, J. J. A defined long-term in vitro tissue engineered model of neuromuscular junctions. Biomaterials 31, 4880-4888, doi:10.1016/j.biomaterials.2010.02.055 (2010).

84 Guo, X. et al. Neuromuscular junction formation between human stem-cellderived motoneurons and rat skeletal muscle in a defined system. Tissue engineering. Part C, Methods 16, 1347-1355, doi:10.1089/ten.TEC.2010.0040 (2010). 
85 Askanas, V. et al. Accumulation of CK-MM is impaired in innervated and contracting cultured muscle fibers of Duchenne muscular dystrophy patients. Life sciences 41, 927-933 (1987).

86 Smith, A. S., Long, C. J., Pirozzi, K. \& Hickman, J. J. A functional system for high-content screening of neuromuscular junctions. Technology 1, 37-48, doi:10.1142/S2339547813500015 (2013).

87 Thomson, S. R. et al. Morphological characteristics of motor neurons do not determine their relative susceptibility to degeneration in a mouse model of severe spinal muscular atrophy. PloS one 7, e52605, doi:10.1371/journal.pone.0052605 (2012).

88 Puttonen, K. A. et al. Generation of Functional Neuromuscular Junctions from Human Pluripotent Stem Cell Lines. Frontiers in cellular neuroscience 9, 473, doi:10.3389/fncel.2015.00473 (2015).

89 Rohwedel, J. et al. Formation of postsynaptic-like membranes during differentiation of embryonic stem cells in vitro. Experimental cell research 239, 214-225, doi:10.1006/excr.1997.3903 (1998).

90 Kostrominova, T. Y., Calve, S., Arruda, E. M. \& Larkin, L. M. Ultrastructure of myotendinous junctions in tendon-skeletal muscle constructs engineered in vitro. Histology and histopathology 24, 541-550 (2009).

91 Lui, P. P. Stem cell technology for tendon regeneration: current status, challenges, and future research directions. Stem cells and cloning : advances and applications 7, 163-174, doi:10.2147/SCCAA.S60832 (2015).

92 Juhas, M., Engelmayr, G. C., Jr., Fontanella, A. N., Palmer, G. M. \& Bursac, N. Biomimetic engineered muscle with capacity for vascular integration and functional maturation in vivo. Proceedings of the National Academy of Sciences of the United States of America 111, 5508-5513, doi:10.1073/pnas.1402723111 (2014).

93 Gholobova, D. et al. Endothelial Network Formation Within Human TissueEngineered Skeletal Muscle. Tissue engineering. Part A 21, 2548-2558, doi:10.1089/ten.TEA.2015.0093 (2015).

94 Carosio, S. et al. Generation of eX vivo-vascularized Muscle Engineered Tissue (X-MET). Scientific reports 3, 1420, doi:10.1038/srep01420 (2013).

95 Levenberg, S. et al. Engineering vascularized skeletal muscle tissue. Nature biotechnology 23, 879-884, doi:10.1038/nbt1109 (2005).

96 Dodson, M. V., Vierck, J. L., Hossner, K. L., Byrne, K. \& McNamara, J. P. The development and utility of a defined muscle and fat co-culture system. Tissue \& cell 29, 517-524 (1997).

97 Shoji, E. et al. Early pathogenesis of Duchenne muscular dystrophy modelled in patient-derived human induced pluripotent stem cells. Scientific reports 5, 12831, doi:10.1038/srep12831 (2015).

98 Abujarour, R. et al. Myogenic differentiation of muscular dystrophy-specific induced pluripotent stem cells for use in drug discovery. Stem cells translational medicine 3, 149-160, doi:10.5966/sctm.2013-0095 (2014).

99 Yasuno, T. et al. Functional analysis of iPSC-derived myocytes from a patient with carnitine palmitoyltransferase II deficiency. Biochemical and biophysical research communications 448, 175-181, doi:10.1016/j.bbrc.2014.04.084 (2014). 
100 Tanaka, A. et al. Efficient and reproducible myogenic differentiation from human iPS cells: prospects for modeling Miyoshi Myopathy in vitro. PloS one 8, e61540, doi:10.1371/journal.pone.0061540 (2013).

101 Kawagoe, S. et al. Generation of induced pluripotent stem (iPS) cells derived from a murine model of Pompe disease and differentiation of Pompe-iPS cells into skeletal muscle cells. Molecular genetics and metabolism 104, 123-128, doi:10.1016/j.ymgme.2011.05.020 (2011).

102 Young, C. S. et al. A Single CRISPR-Cas9 Deletion Strategy that Targets the Majority of DMD Patients Restores Dystrophin Function in hiPSC-Derived Muscle Cells. Cell stem cell, doi:10.1016/j.stem.2016.01.021 (2016).

103 Tran, T., Andersen, R., Sherman, S. P. \& Pyle, A. D. Insights into skeletal muscle development and applications in regenerative medicine. International review of cell and molecular biology 300, 51-83, doi:10.1016/B978-0-12-405210-9.00002-3 (2013).

$104 \mathrm{Li}, \mathrm{H}$. L. et al. Precise correction of the dystrophin gene in duchenne muscular dystrophy patient induced pluripotent stem cells by TALEN and CRISPR-Cas9. Stem cell reports 4, 143-154, doi:10.1016/j.stemcr.2014.10.013 (2015).

105 Yokota, T., Pistilli, E., Duddy, W. \& Nagaraju, K. Potential of oligonucleotidemediated exon-skipping therapy for Duchenne muscular dystrophy. Expert opinion on biological therapy 7, 831-842, doi:10.1517/14712598.7.6.831 (2007).

106 Kazuki, Y. et al. Complete genetic correction of ips cells from Duchenne muscular dystrophy. Molecular therapy : the journal of the American Society of Gene Therapy 18, 386-393, doi:10.1038/mt.2009.274 (2010).

107 van Deutekom, J. C. et al. Local dystrophin restoration with antisense oligonucleotide PRO051. The New England journal of medicine 357, 2677-2686, doi:10.1056/NEJMoa073108 (2007).

108 Skuk, D. \& Tremblay, J. P. Intramuscular cell transplantation as a potential treatment of myopathies: clinical and preclinical relevant data. Expert opinion on biological therapy 11, 359-374, doi:10.1517/14712598.2011.548800 (2011).

109 Ostrovidov, S. et al. Stem Cell Differentiation Toward the Myogenic Lineage for Muscle Tissue Regeneration: A Focus on Muscular Dystrophy. Stem cell reviews 11, 866-884, doi:10.1007/s12015-015-9618-4 (2015).

110 Bursac, N., Juhas, M. \& Rando, T. A. Synergizing Engineering and Biology to Treat and Model Skeletal Muscle Injury and Disease. Annual review of biomedical engineering 17, 217-242, doi:10.1146/annurev-bioeng-071114040640 (2015).

111 Liao, H. \& Zhou, G. Q. Development and progress of engineering of skeletal muscle tissue. Tissue engineering. Part B, Reviews 15, 319-331, doi:10.1089/ten.teb.2009.0092 (2009).

112 Koning, M., Harmsen, M. C., van Luyn, M. J. \& Werker, P. M. Current opportunities and challenges in skeletal muscle tissue engineering. Journal of tissue engineering and regenerative medicine 3, 407-415, doi:10.1002/term.190 (2009).

113 Tourovskaia, A., Figueroa-Masot, X. \& Folch, A. Long-term microfluidic cultures of myotube microarrays for high-throughput focal stimulation. Nature protocols $\mathbf{1}$, 1092-1104, doi:10.1038/nprot.2006.123 (2006). 
114 Reimann, J. et al. Pax7 distribution in human skeletal muscle biopsies and myogenic tissue cultures. Cell and tissue research 315, 233-242, doi:10.1007/s00441-003-0833-y (2004).

115 Kottlors, M. \& Kirschner, J. Elevated satellite cell number in Duchenne muscular dystrophy. Cell and tissue research 340, 541-548, doi:10.1007/s00441-0100976-6 (2010).

116 Lepper, C., Partridge, T. A. \& Fan, C. M. An absolute requirement for Pax7positive satellite cells in acute injury-induced skeletal muscle regeneration. Development 138, 3639-3646, doi:10.1242/dev.067595 (2011).

117 Sambasivan, R. et al. Pax7-expressing satellite cells are indispensable for adult skeletal muscle regeneration. Development 138, 3647-3656, doi:10.1242/dev.067587 (2011).

118 Murphy, M. M., Lawson, J. A., Mathew, S. J., Hutcheson, D. A. \& Kardon, G. Satellite cells, connective tissue fibroblasts and their interactions are crucial for muscle regeneration. Development 138, 3625-3637, doi:10.1242/dev.064162 (2011).

119 Roca, I., Requena, J., Edel, M. J. \& Alvarez-Palomo, A. B. Myogenic Precursors from iPS Cells for Skeletal Muscle Cell Replacement Therapy. Journal of clinical medicine 4, 243-259, doi:10.3390/jcm4020243 (2015).

120 Mendell, J. R. et al. Myoblast transfer in the treatment of Duchenne's muscular dystrophy. The New England journal of medicine 333, 832-838, doi:10.1056/NEJM199509283331303 (1995).

121 Rando, T. A., Pavlath, G. K. \& Blau, H. M. The fate of myoblasts following transplantation into mature muscle. Experimental cell research 220, 383-389, doi:10.1006/excr.1995.1329 (1995).

122 Gussoni, E., Blau, H. M. \& Kunkel, L. M. The fate of individual myoblasts after transplantation into muscles of DMD patients. Nature medicine 3, 970-977 (1997).

123 Montarras, D. et al. Direct isolation of satellite cells for skeletal muscle regeneration. Science 309, 2064-2067, doi:10.1126/science.1114758 (2005).

124 Collins, C. A. et al. Stem cell function, self-renewal, and behavioral heterogeneity of cells from the adult muscle satellite cell niche. Cell 122, 289-301, doi:10.1016/j.cell.2005.05.010 (2005).

125 Sacco, A., Doyonnas, R., Kraft, P., Vitorovic, S. \& Blau, H. M. Self-renewal and expansion of single transplanted muscle stem cells. Nature 456, 502-506, doi:10.1038/nature07384 (2008).

126 Boldrin, L. \& Morgan, J. E. Human satellite cells: identification on human muscle fibres. PLoS currents 3, RRN1294, doi:10.1371/currents.RRN1294 (2011).

127 Marg, A. et al. Human satellite cells have regenerative capacity and are genetically manipulable. The Journal of clinical investigation 124, 4257-4265, doi:10.1172/JCl63992 (2014).

$128 \mathrm{Xu}, \mathrm{X}$. et al. Human Satellite Cell Transplantation and Regeneration from Diverse Skeletal Muscles. Stem cell reports 5, 419-434, doi:10.1016/j.stemcr.2015.07.016 (2015). 
129 Gilbert, P. M. et al. Substrate elasticity regulates skeletal muscle stem cell selfrenewal in culture. Science 329, 1078-1081, doi:10.1126/science.1191035 (2010).

130 Tierney, M. T. G., A.; Boscolo Sesillo, F.; Sala, D.;Spenlé, C.; Orend, G.; Sacco, A. Autonomous Extracellular Matrix Remodeling Controls a Progressive Adaptation in Muscle Stem Cell Regenerative Capacity during Development. Cell reports, 1-13 (2016).

131 Charville, G. W. et al. Ex Vivo Expansion and In Vivo Self-Renewal of Human Muscle Stem Cells. Stem cell reports 5, 621-632, doi:10.1016/j.stemcr.2015.08.004 (2015).

132 Meng, J., Adkin, C. F., Xu, S. W., Muntoni, F. \& Morgan, J. E. Contribution of human muscle-derived cells to skeletal muscle regeneration in dystrophic host mice. PloS one 6, e17454, doi:10.1371/journal.pone.0017454 (2011).

133 Tajbakhsh, S. Skeletal muscle stem cells in developmental versus regenerative myogenesis. Journal of internal medicine 266, 372-389, doi:10.1111/j.13652796.2009.02158.x (2009).

134 Baker, R. K. \& Lyons, G. E. Embryonic stem cells and in vitro muscle development. Current topics in developmental biology 33, 263-279 (1996).

135 Darabi, R., Santos, F. N. \& Perlingeiro, R. C. The therapeutic potential of embryonic and adult stem cells for skeletal muscle regeneration. Stem cell reviews 4, 217-225, doi:10.1007/s12015-008-9023-3 (2008).

136 Salani, S. et al. Generation of skeletal muscle cells from embryonic and induced pluripotent stem cells as an in vitro model and for therapy of muscular dystrophies. Journal of cellular and molecular medicine 16, 1353-1364, doi:10.1111/j.1582-4934.2011.01498.x (2012).

137 Vilquin, J. T. Converting pathological cells to therapeutic ones: an odyssey through pluripotency. Molecular therapy : the journal of the American Society of Gene Therapy 20, 2012-2014, doi:10.1038/mt.2012.219 (2012).

138 Swierczek, B., Ciemerych, M. A. \& Archacka, K. From pluripotency to myogenesis: a multistep process in the dish. Journal of muscle research and cell motility, doi:10.1007/s10974-015-9436-y (2015).

139 Grabowska, I., Archacka, K., Czerwinska, A. M., Krupa, M. \& Ciemerych, M. A. Mouse and human pluripotent stem cells and the means of their myogenic differentiation. Results and problems in cell differentiation 55, 321-356, doi:10.1007/978-3-642-30406-4_18 (2012).

140 Wilschut, K. J., Ling, V. B. \& Bernstein, H. S. Concise review: stem cell therapy for muscular dystrophies. Stem cells translational medicine 1, 833-842, doi:10.5966/sctm.2012-0071 (2012).

141 Abujarour, R. \& Valamehr, B. Generation of skeletal muscle cells from pluripotent stem cells: advances and challenges. Frontiers in cell and developmental biology 3, 29, doi:10.3389/fcell.2015.00029 (2015).

142 Dekel, I., Magal, Y., Pearson-White, S., Emerson, C. P. \& Shani, M. Conditional conversion of ES cells to skeletal muscle by an exogenous MyoD1 gene. The New biologist 4, 217-224 (1992). 
143 Shani, M. et al. The consequences of a constitutive expression of MyoD1 in ES cells and mouse embryos. Symposia of the Society for Experimental Biology 46, 19-36 (1992).

144 Davis, R. L., Weintraub, H. \& Lassar, A. B. Expression of a single transfected cDNA converts fibroblasts to myoblasts. Cell 51, 987-1000 (1987).

145 Comai, G. \& Tajbakhsh, S. Molecular and cellular regulation of skeletal myogenesis. Current topics in developmental biology 110, 1-73, doi:10.1016/B978-0-12-405943-6.00001-4 (2014).

146 Darabi, R. et al. Functional skeletal muscle regeneration from differentiating embryonic stem cells. Nature medicine 14, 134-143, doi:10.1038/nm1705 (2008).

147 Rao, L. et al. Highly efficient derivation of skeletal myotubes from human embryonic stem cells. Stem cell reviews 8, 1109-1119, doi:10.1007/s12015-0129413-4 (2012).

148 Goudenege, S. et al. Myoblasts derived from normal hESCs and dystrophic hiPSCs efficiently fuse with existing muscle fibers following transplantation. Molecular therapy : the journal of the American Society of Gene Therapy 20, 2153-2167, doi:10.1038/mt.2012.188 (2012).

149 Albini, S. et al. Epigenetic reprogramming of human embryonic stem cells into skeletal muscle cells and generation of contractile myospheres. Cell reports $\mathbf{3}$, 661-670, doi:10.1016/j.celrep.2013.02.012 (2013).

150 Darabi, R. et al. Human ES- and iPS-derived myogenic progenitors restore DYSTROPHIN and improve contractility upon transplantation in dystrophic mice. Cell stem cell 10, 610-619, doi:10.1016/j.stem.2012.02.015 (2012).

151 Fougerousse, F. et al. Six and Eya expression during human somitogenesis and MyoD gene family activation. Journal of muscle research and cell motility 23, 255-264 (2002).

152 Goulding, M. D., Chalepakis, G., Deutsch, U., Erselius, J. R. \& Gruss, P. Pax-3, a novel murine DNA binding protein expressed during early neurogenesis. The EMBO journal 10, 1135-1147 (1991).

153 Jostes, B., Walther, C. \& Gruss, P. The murine paired box gene, Pax7, is expressed specifically during the development of the nervous and muscular system. Mechanisms of development 33, 27-37 (1990).

154 Gerard, M. et al. PAX-genes expression during human embryonic development, a preliminary report. Comptes rendus de l'Academie des sciences. Serie III, Sciences de la vie 318, 57-66 (1995).

155 Terzic, J. \& Saraga-Babic, M. Expression pattern of PAX3 and PAX6 genes during human embryogenesis. The International journal of developmental biology 43, 501-508 (1999).

156 Skoglund, G. et al. Physiological and ultrastructural features of human induced pluripotent and embryonic stem cell-derived skeletal myocytes in vitro. Proceedings of the National Academy of Sciences of the United States of America 111, 8275-8280, doi:10.1073/pnas.1322258111 (2014).

157 Armulik, A., Genove, G. \& Betsholtz, C. Pericytes: developmental, physiological, and pathological perspectives, problems, and promises. Developmental cell 21, 193-215, doi:10.1016/j.devcel.2011.07.001 (2011). 
158 Peault, B. et al. Stem and progenitor cells in skeletal muscle development, maintenance, and therapy. Molecular therapy : the journal of the American Society of Gene Therapy 15, 867-877, doi:10.1038/mt.sj.6300145 (2007).

159 Dellavalle, A. et al. Pericytes of human skeletal muscle are myogenic precursors distinct from satellite cells. Nature cell biology 9, 255-267, doi:10.1038/ncb1542 (2007).

160 Tedesco, F. S. et al. Transplantation of genetically corrected human iPSCderived progenitors in mice with limb-girdle muscular dystrophy. Science translational medicine 4, 140ra189, doi:10.1126/scitranslmed.3003541 (2012).

161 Moretti, A., Laugwitz, K. L., Dorn, T., Sinnecker, D. \& Mummery, C. Pluripotent stem cell models of human heart disease. Cold Spring Harbor perspectives in medicine 3, doi:10.1101/cshperspect.a014027 (2013).

162 Robertson, C., Tran, D. D. \& George, S. C. Concise review: maturation phases of human pluripotent stem cell-derived cardiomyocytes. Stem cells 31, 829-837, doi:10.1002/stem.1331 (2013).

163 Bock, C. et al. Reference Maps of human ES and iPS cell variation enable highthroughput characterization of pluripotent cell lines. Cell 144, 439-452, doi:10.1016/j.cell.2010.12.032 (2011).

164 Boulting, G. L. et al. A functionally characterized test set of human induced pluripotent stem cells. Nature biotechnology 29, 279-286, doi:10.1038/nbt.1783 (2011).

165 Halme, D. G. \& Kessler, D. A. FDA regulation of stem-cell-based therapies. The New England journal of medicine 355, 1730-1735, doi:10.1056/NEJMhpr063086 (2006).

166 Vandenburgh, H. High-content drug screening with engineered musculoskeletal tissues. Tissue engineering. Part $B$, Reviews 16, 55-64, doi:10.1089/ten.TEB.2009.0445 (2010).

167 Desbordes, S. C. \& Studer, L. Adapting human pluripotent stem cells to highthroughput and high-content screening. Nature protocols 8, 111-130, doi:10.1038/nprot.2012.139 (2013).

168 Watanabe, K. et al. A ROCK inhibitor permits survival of dissociated human embryonic stem cells. Nature biotechnology 25, 681-686, doi:10.1038/nbt1310 (2007).

169 Kleinman, H. K. et al. Basement membrane complexes with biological activity. Biochemistry 25, 312-318 (1986).

170 Hauschka, S. D. \& Konigsberg, I. R. The influence of collagen on the development of muscle clones. Proceedings of the National Academy of Sciences of the United States of America 55, 119-126 (1966).

171 Kuhl, U., Ocalan, M., Timpl, R. \& von der Mark, K. Role of laminin and fibronectin in selecting myogenic versus fibrogenic cells from skeletal muscle cells in vitro. Developmental biology 117, 628-635 (1986).

172 von der Mark, K. \& Ocalan, M. Antagonistic effects of laminin and fibronectin on the expression of the myogenic phenotype. Differentiation; research in biological diversity 40, 150-157 (1989).

173 Maley, M. A., Davies, M. J. \& Grounds, M. D. Extracellular matrix, growth factors, genetics: their influence on cell proliferation and myotube formation in primary 
cultures of adult mouse skeletal muscle. Experimental cell research 219, 169179, doi:10.1006/excr.1995.1217 (1995).

174 Pinset, C. \& Whalen, R. G. Induction of myogenic differentiation in serum-free medium does not require DNA synthesis. Developmental biology 108, 284-289 (1985).

175 Goto, S., Miyazaki, K., Funabiki, T. \& Yasumitsu, H. Serum-free culture conditions for analysis of secretory proteinases during myogenic differentiation of mouse C2C12 myoblasts. Analytical biochemistry 272, 135-142, doi:10.1006/abio.1999.4163 (1999).

176 Reiss, K. \& Korohoda, W. The formation of myotubes in cultures of chick embryo myogenic cells in serum-free medium is induced by the insulin pulse treatment. Folia histochemica et cytobiologica / Polish Academy of Sciences, Polish Histochemical and Cytochemical Society 26, 133-141 (1988).

177 Herrmann, B. G., Labeit, S., Poustka, A., King, T. R. \& Lehrach, H. Cloning of the $\mathrm{T}$ gene required in mesoderm formation in the mouse. Nature 343, 617-622, doi:10.1038/343617a0 (1990).

178 Kispert, A. \& Herrmann, B. G. Immunohistochemical analysis of the Brachyury protein in wild-type and mutant mouse embryos. Developmental biology 161, 179-193, doi:10.1006/dbio.1994.1019 (1994).

179 Yoon, J. K. \& Wold, B. The bHLH regulator pMesogenin1 is required for maturation and segmentation of paraxial mesoderm. Genes \& development 14, 3204-3214 (2000).

180 Yoon, J. K., Moon, R. T. \& Wold, B. The bHLH class protein pMesogenin1 can specify paraxial mesoderm phenotypes. Developmental biology 222, 376-391, doi:10.1006/dbio.2000.9717 (2000).

181 Sassoon, D. et al. Expression of two myogenic regulatory factors myogenin and MyoD1 during mouse embryogenesis. Nature 341, 303-307, doi:10.1038/341303a0 (1989).

182 Braun, T. \& Arnold, H. H. ES-cells carrying two inactivated myf-5 alleles form skeletal muscle cells: activation of an alternative myf-5-independent differentiation pathway. Developmental biology 164, 24-36, doi:10.1006/dbio.1994.1177 (1994).

183 Yablonka-Reuveni, Z. \& Paterson, B. M. MyoD and myogenin expression patterns in cultures of fetal and adult chicken myoblasts. The journal of histochemistry and cytochemistry : official journal of the Histochemistry Society 49, 455-462 (2001).

184 Lyons, G. E., Ontell, M., Cox, R., Sassoon, D. \& Buckingham, M. The expression of myosin genes in developing skeletal muscle in the mouse embryo. The Journal of cell biology 111, 1465-1476 (1990).

185 Seale, P. et al. Pax7 is required for the specification of myogenic satellite cells. Cell 102, 777-786 (2000).

186 Zammit, P. S. et al. Pax7 and myogenic progression in skeletal muscle satellite cells. Journal of cell science 119, 1824-1832, doi:10.1242/jcs.02908 (2006).

187 McCain, M. L., Agarwal, A., Nesmith, H. W., Nesmith, A. P. \& Parker, K. K. Micromolded gelatin hydrogels for extended culture of engineered cardiac 
tissues. Biomaterials 35, 5462-5471, doi:10.1016/j.biomaterials.2014.03.052 (2014).

188 Pasqualini, F. S., Sheehy, S. P., Agarwal, A., Aratyn-Schaus, Y. \& Parker, K. K. Structural phenotyping of stem cell-derived cardiomyocytes. Stem cell reports 4 , 340-347, doi:10.1016/j.stemcr.2015.01.020 (2015). 


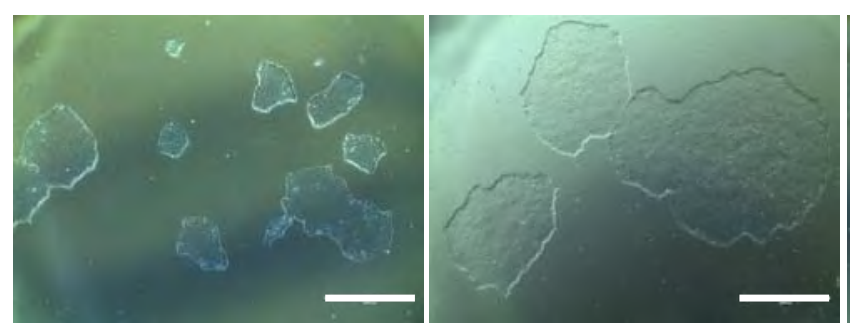

Step 1

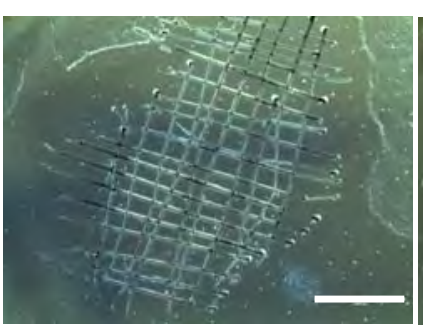

Step 3

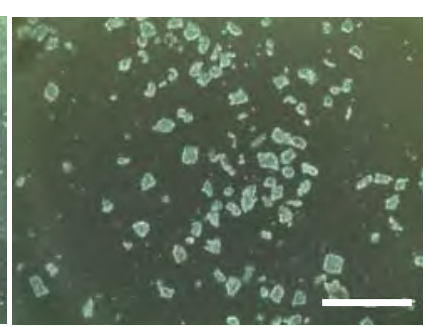

Step 4

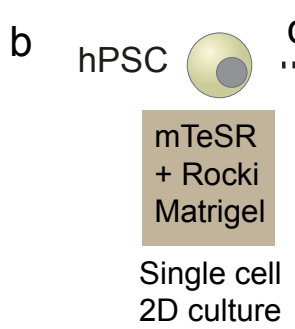

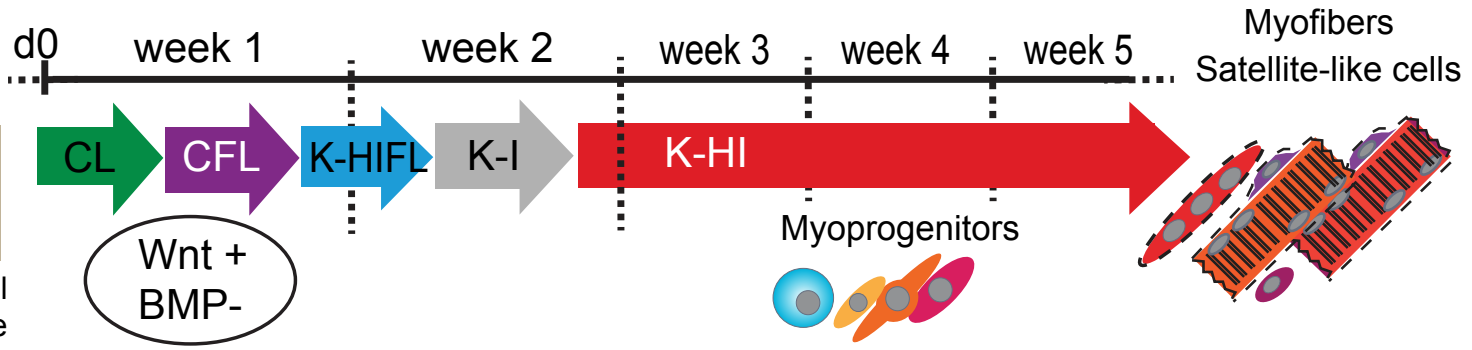

Steps 5-19

Step 20

Step 21 Step 22 Step 23

Step 24

Step 25

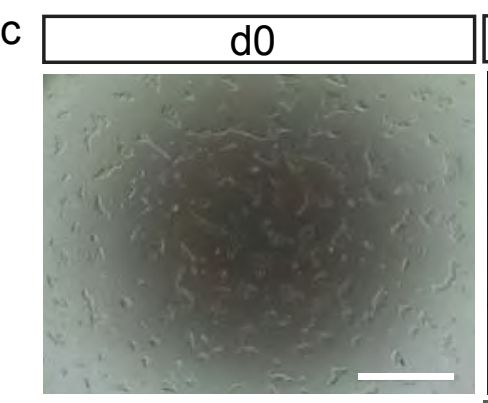

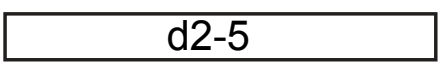
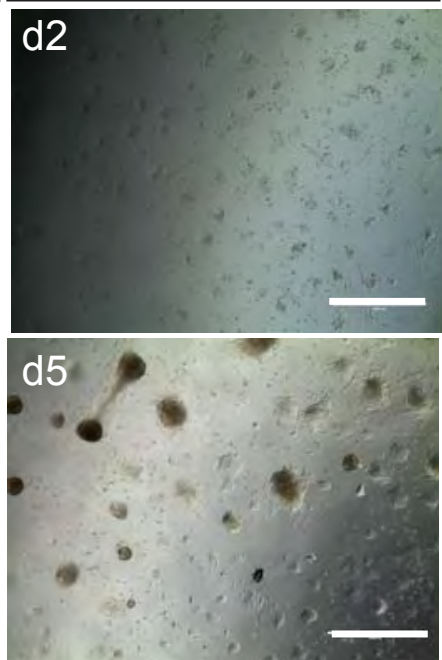
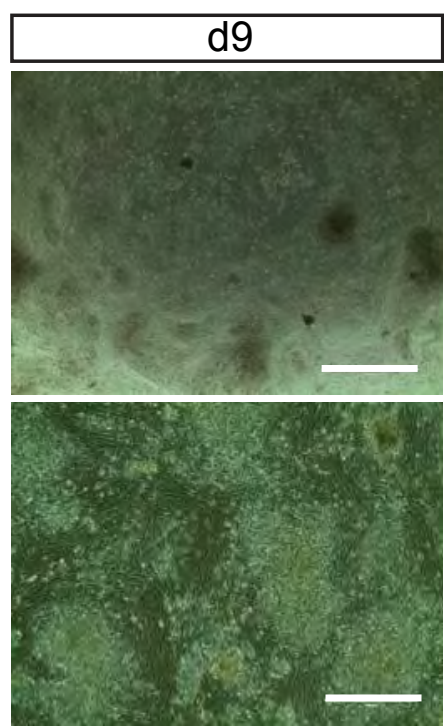

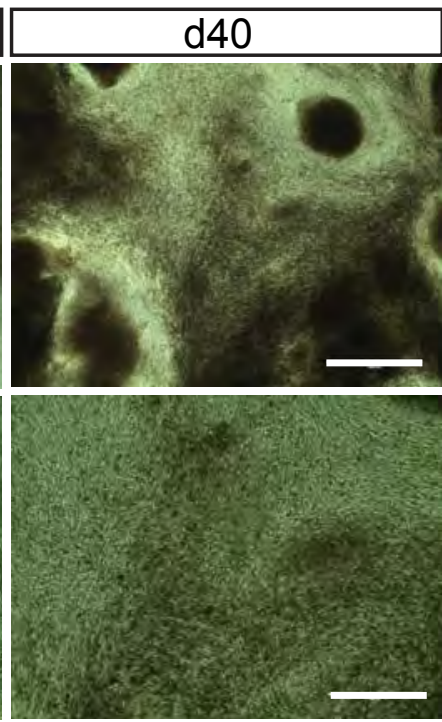

Fig_1_Chal_AlTanoury et al 

mesoderm progenitors
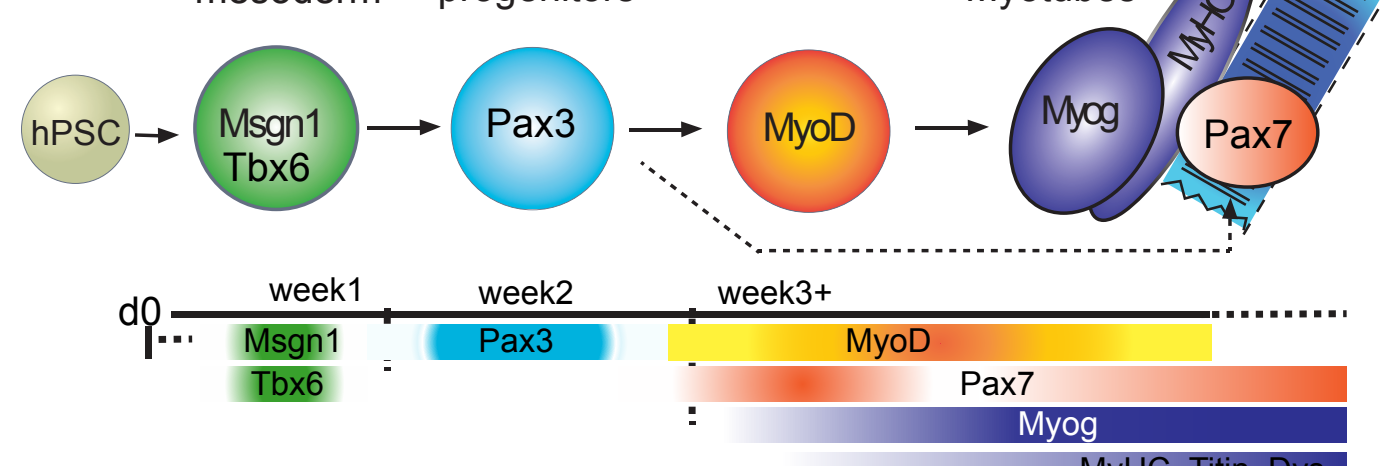

MyHC, Titin, Dys

Step $20 \quad$ Steps 20-21 Steps 22-24 Step 25 / 54

Primary differentiation
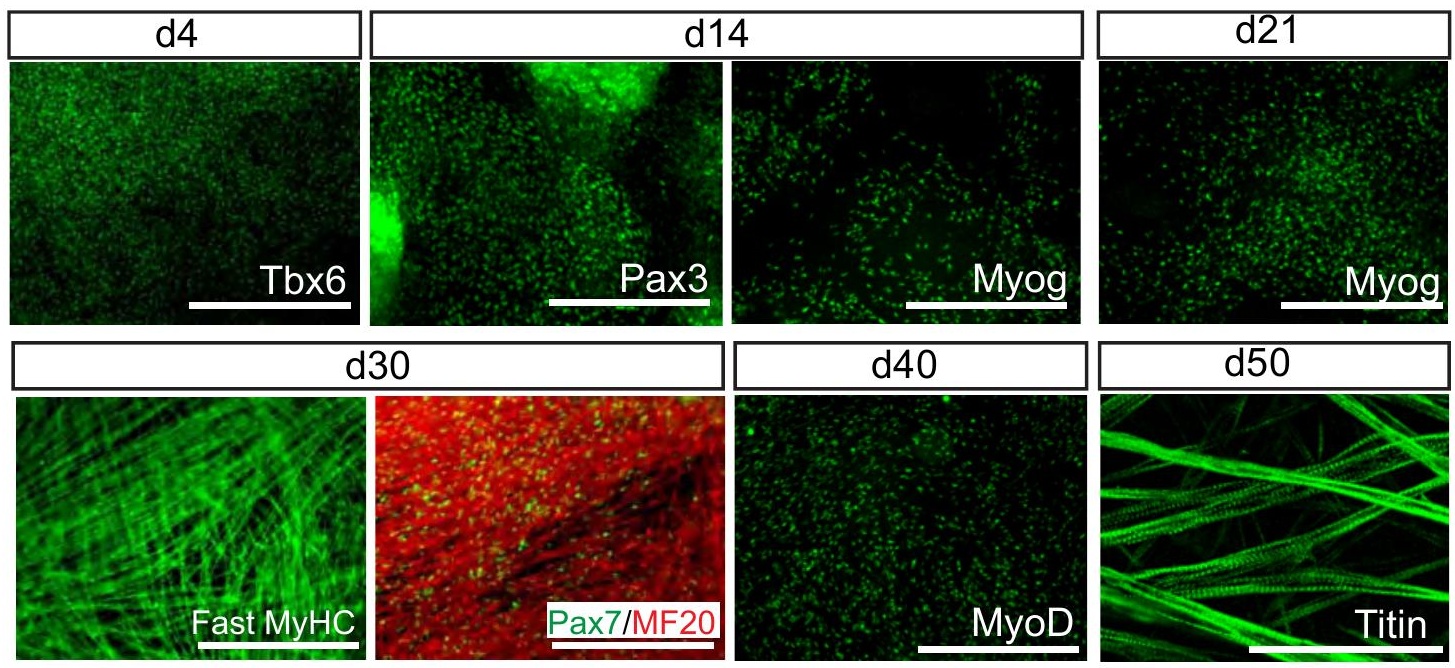

Fig_2_Chal_AlTanoury et al 
$\mathrm{a}$

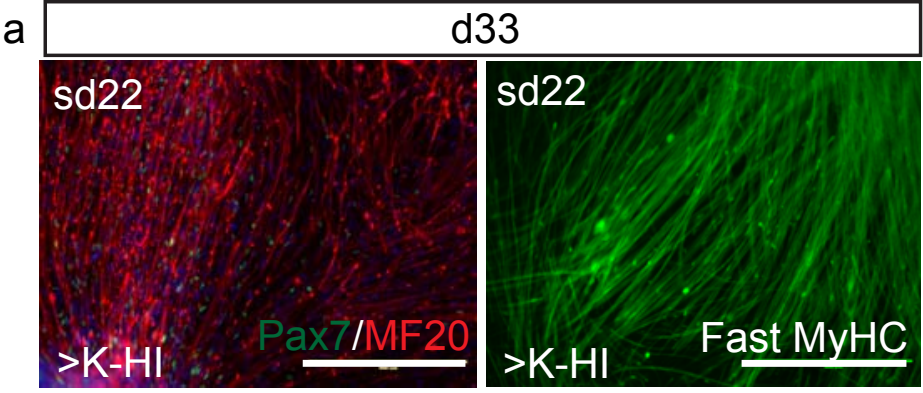

b

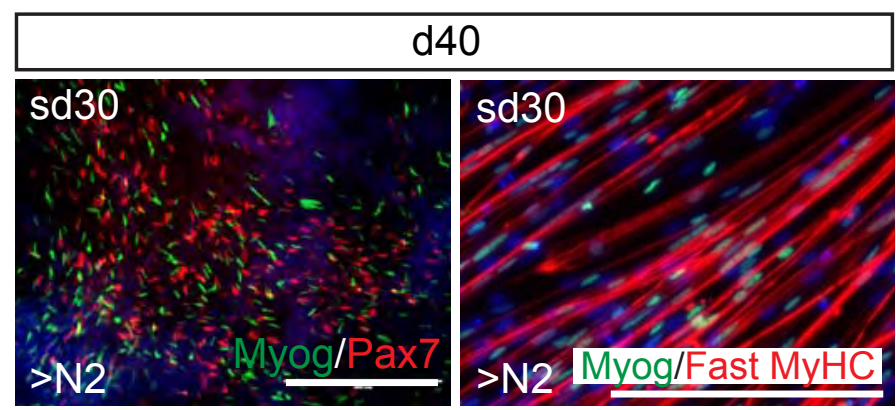

c

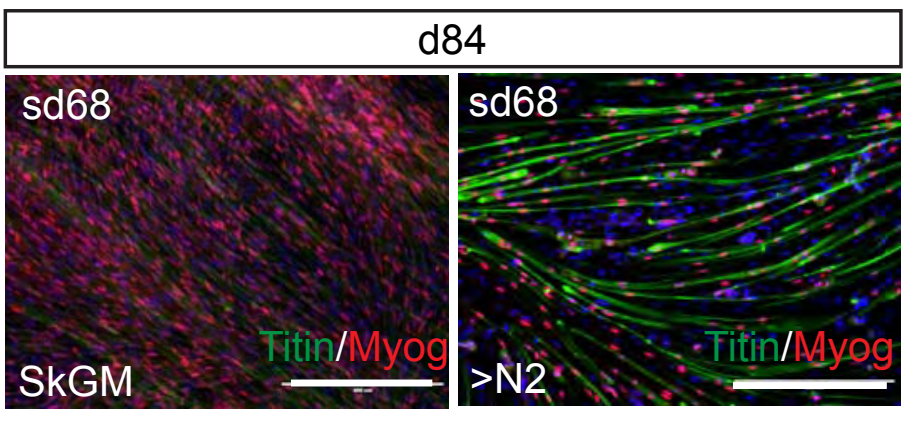

$d$

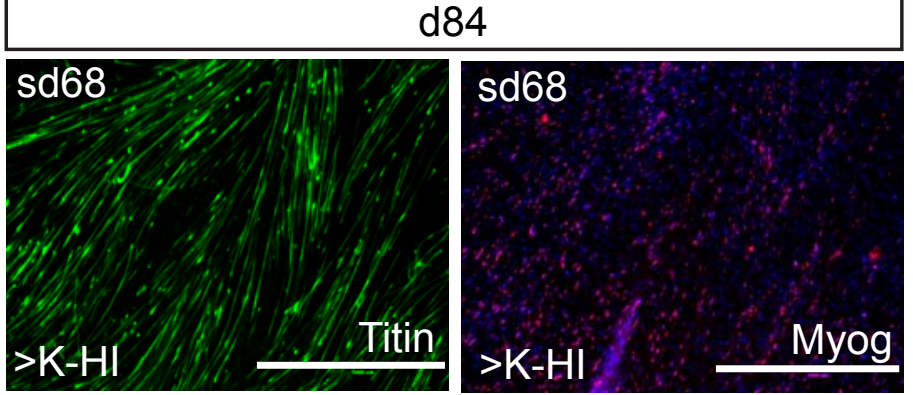

\section{sd68}

e

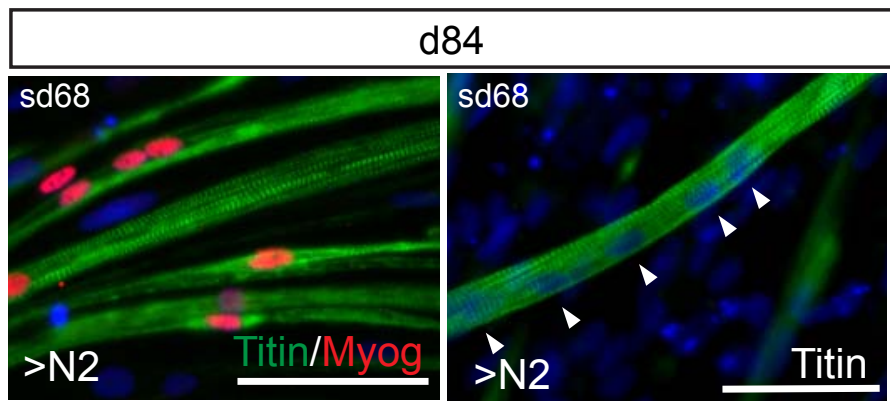

f

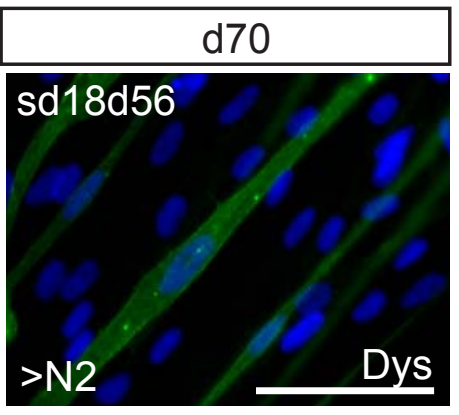

$\mathrm{g}$

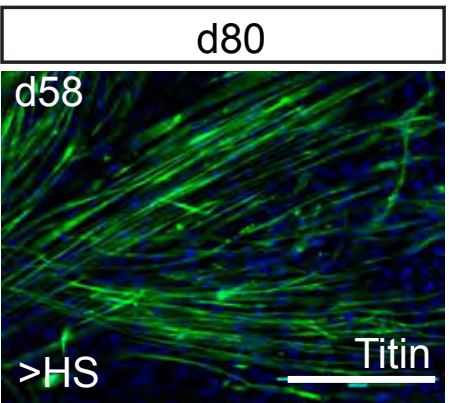

Fig_4_Chal_AlTanoury et al 


\section{a Muscle construct}
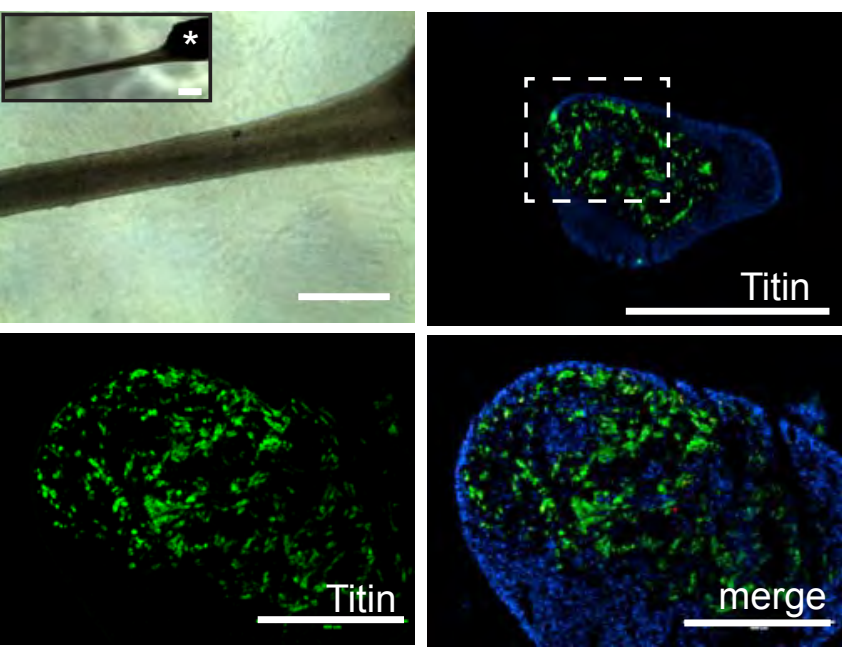

C Micropatterned surface
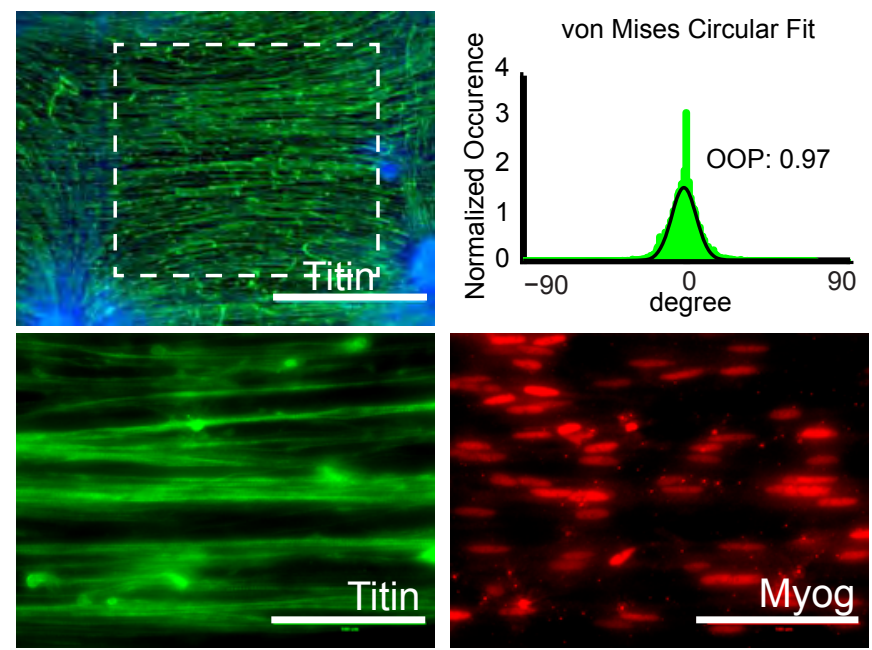
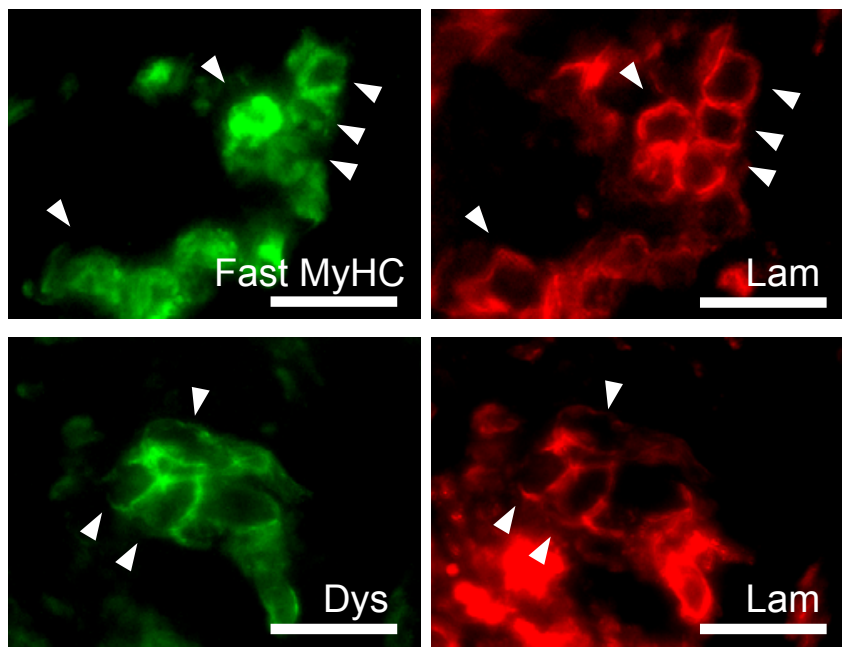

d

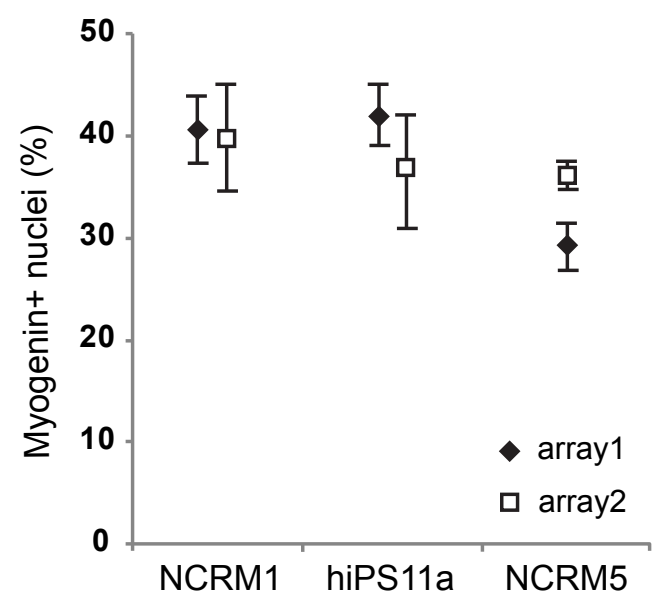

Fig_5_Chal_AlTanoury et al 